University of Louisville

ThinkIR: The University of Louisville's Institutional Repository

Electronic Theses and Dissertations

$12-2018$

\title{
Student perception of the effects of out of school suspension on academic motivation.
}

Dawn Boone Roseberry

University of Louisville

Follow this and additional works at: https://ir.library.louisville.edu/etd

Part of the Education Commons

\section{Recommended Citation}

Roseberry, Dawn Boone, "Student perception of the effects of out of school suspension on academic motivation." (2018). Electronic Theses and Dissertations. Paper 3107.

https://doi.org/10.18297/etd/3107

This Doctoral Dissertation is brought to you for free and open access by ThinkIR: The University of Louisville's Institutional Repository. It has been accepted for inclusion in Electronic Theses and Dissertations by an authorized administrator of ThinkIR: The University of Louisville's Institutional Repository. This title appears here courtesy of the author, who has retained all other copyrights. For more information, please contact thinkir@louisville.edu. 


\title{
STUDENT PERCEPTION OF THE EFFECTS OF OUT OF SCHOOL SUSPENSION ON ACADEMIC MOTIVATION
}

\author{
By \\ Dawn Boone Roseberry \\ B.A., University of Louisville, 1987 \\ M.Ed., University of Louisville, 1996 \\ M.Ed., Spalding University, 2013
}

\begin{abstract}
A Dissertation
Submitted to the Faculty of the

College of Education and Human Development of the University of Louisville

In Partial Fulfillment of the Requirements

For the Degree of
\end{abstract}

Doctor of Education

In Educational Leadership and Organizational Development

Department of Education Leadership, Evaluation, and Organizational Development University of Louisville

Louisville, Kentucky

December 2018 
Copyright 2018 by Dawn Boone Roseberry

All rights reserved 



\title{
STUDENT PERCEPTION OF THE EFFECTS OF OUT OF SCHOOL SUSPENSION ON ACADEMIC MOTIVATION
}

\author{
By \\ Dawn Boone Roseberry \\ B.A., University of Louisville, 1987 \\ M.A., University of Louisville, 1996 \\ M.A., Spalding University, 2013 \\ A Dissertation Approved on
}

October 5, 2018

By the following Dissertation Committee:

Mary Brydon-Miller, Ph.D

Blake Haselton, Ph.D

Debbie Powers, Ed.D

Harrie Buecker, Ed.D 


\section{DEDICATION}

This dissertation is dedicated to my sons, Aaron and Luke, who are my pride and joy. I thank my dear Lord and Savior each day for blessing me with two amazing sons. They have supported me through this journey with patience and encouragement each step of the way. Every time I would hear them tell a friend, "my mom is working on her doctorate", I would smile and my motivation to finish this process would re-ignite! 


\section{ACKNOWLEDGEMENTS}

I would like to thank my Lord and Savior for guiding me through this process. $\mathrm{He}$ is my strength and my salvation. To him, I give all the glory! I would like to thank my parents for instilling in me the importance of education and hard work. I would like to thank Dr. Brydon-Miller for her leadership and patience with me as my dissertation chair. She always had the "right" words for me when I would doubt myself. My other committee members were amazing and I have learned so much from these talented, brilliant educators through this journey. Thnk you so much Dr. Blake Haselton, Dr. Debbie Powers, and Dr. Harrie Buecker. My writing partner, Carla, has been my motivator and rock through this. We have laughed and cried together. We have spent thousands of dollars at Panera at our favorite table in the back. To block 18 for the friendships we have formed, the knowledge we have shared and the forever bond that we will always have from this experience.

To my family for their unwavering support. If my dad had asked me one more time when I was going to finish this thing, I think I might have screamed! (Just kidding, dad, not kidding really) Pat, my sister/cheerleader, who always made me feel so much smarter than I am, I absolutely adore you and thank you for letting me cry on your shoulder after my tireless writing sessions. To my co-workers and friends at work who were always by my side cheering me to the finish. 
To my Lukey, for all of the dishes you did, laundry you washed, trash you took out, meals you had to fix yourself and eat alone, and for your patience when I got home as I fell into bed, you never complained. I am so proud to call you my son. To my Airbear, you always encouraged me and told me how proud you were of me to pursue this degree. I guess it is a competition now as you finish your masters degree in Chemical Engineering. I only hope you start on your doctorate at a much earlier age than I did! I think the longer you wait, the harder it gets! 


\begin{abstract}

\section{STUDENT PERCEPTION OF THE EFFECTS OF OUT OF SCHOOL SUSPENSION ON ACADEMIC MOTIVATION}

Dawn B. Roseberry

October 5, 2018

Historically, the response to rule violations and misbehavior in schools was to punish students by using methods such as exclusionary discipline. Exclusionary discipline may lead to poor academic outcomes for the student, increased likelihood of dropping out of school, and an introduction to the criminal justice system (Cueller and Markowitz, 2015). Being suspended from school also increases the chances a student will feel disconnected, intensify conflict with adults, and impact a youth's choice to engage in criminal activities (Skiba et al., 2006). Researchers have concluded that suspension is also a predictor of future suspensions, not a deterrent (Rafaele \& Mendez, 2003). Use of suspension is associated with lower academic achievement, an increased risk of deviant behavior and impacts on time graduation (Losen \& Skiba, 2015). When students experience out of school suspension and then return to school, many feel they cannot catch back up to their peers. This may be the final straw as a student struggles to decide whether they should drop out of school (Bloomberg, 2004).

This qualitative study used a phenomenological inquiry design. Individual semistructured interviews were conducted with students who had been suspended for at least six days during the school year to identify perceptions about out of school suspension and 
the impact on academic motivation. Specifically this study examined whether this perception changes based on the severity of the offense. Finally, this research helped determine whether there is a connection between the culture of the school community and out of school suspension. These findings may help with the development of future disciplinary policies for high schools.

Keywords: Out of school suspension, exclusionary discipline, academic motivation, school discipline policy 
TABLE OF CONTENTS

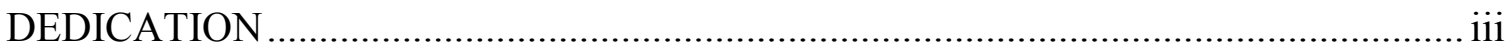

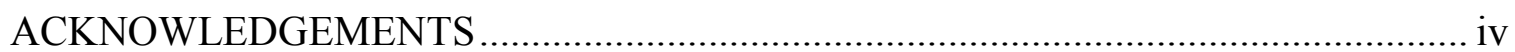

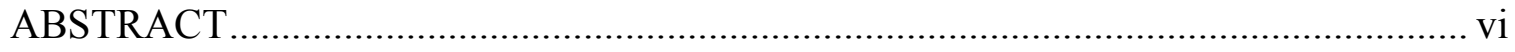

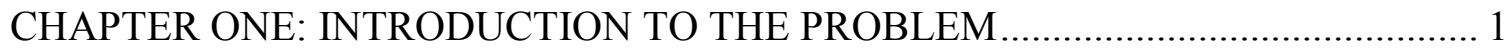

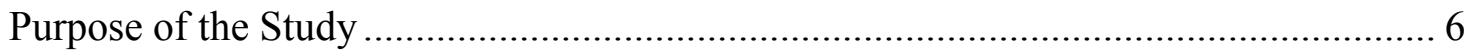

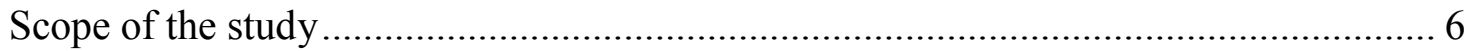

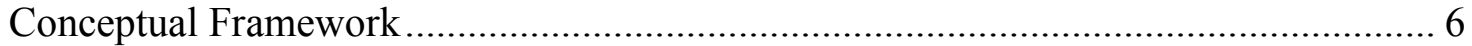

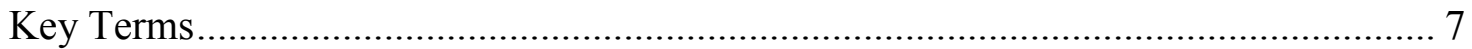

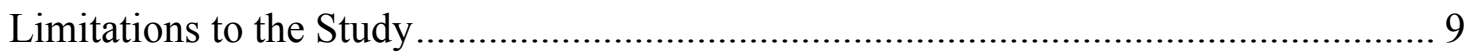

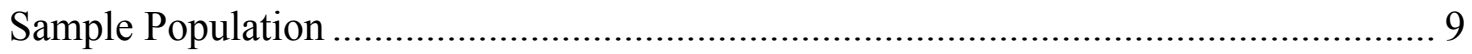

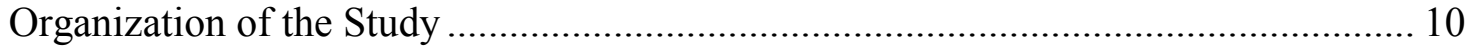

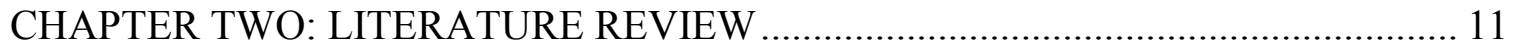

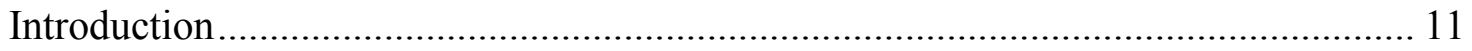

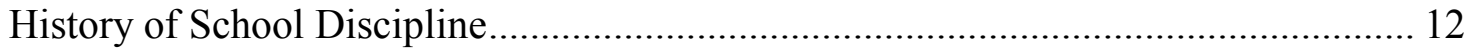

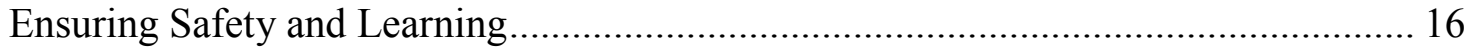


Suspendable Offenses ............................................................................... 19

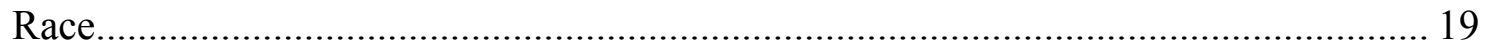

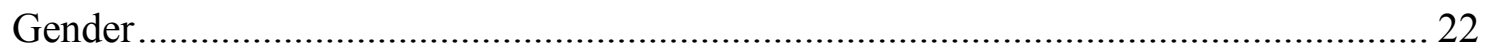

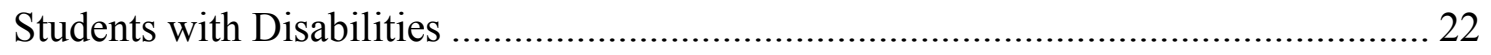

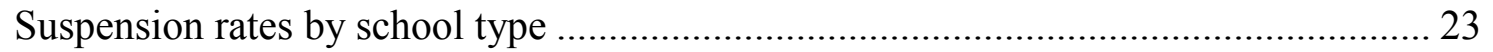

Out of School Suspensions and Educational Outcomes ....................................... 24

Academic Achievement .................................................................................... 24

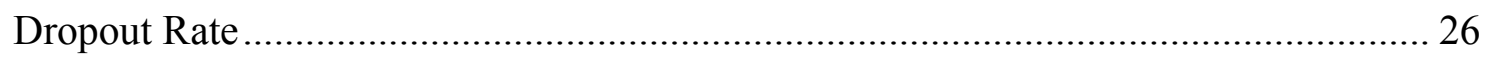

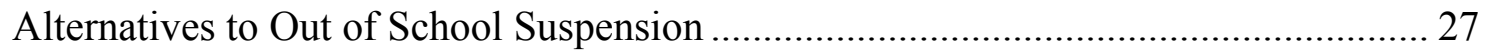

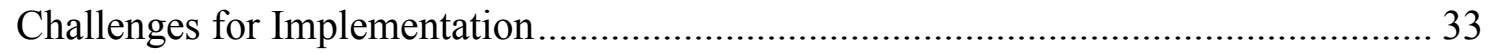

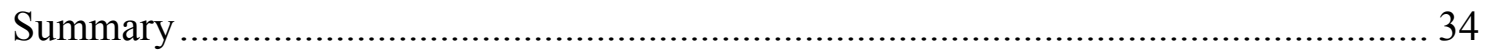

CHAPTER THREE: METHODOLOGY ............................................................ 36

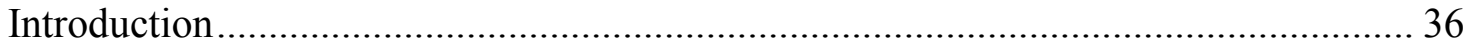

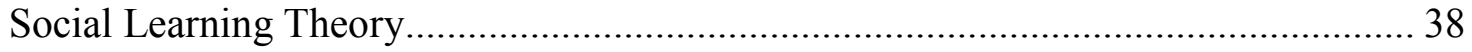

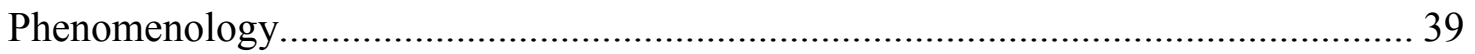

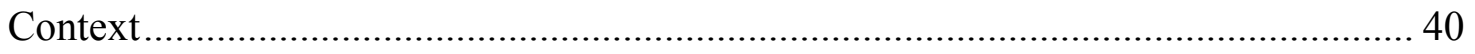

Sample Design /Participants ............................................................................... 41

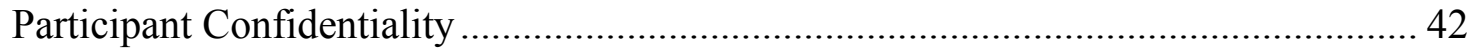

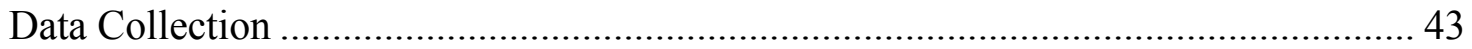




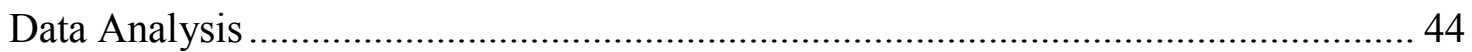

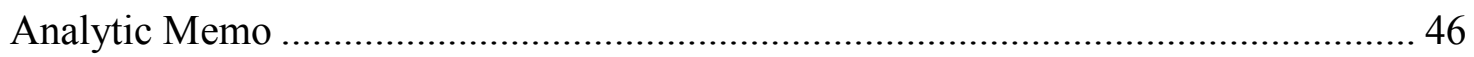

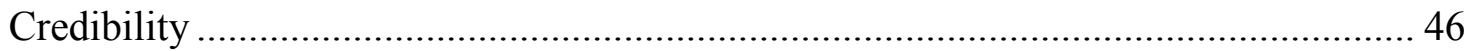

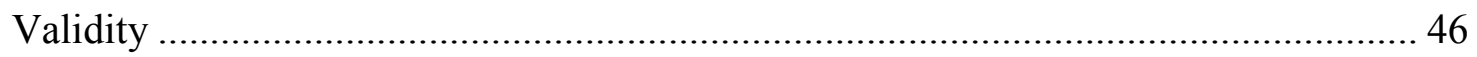

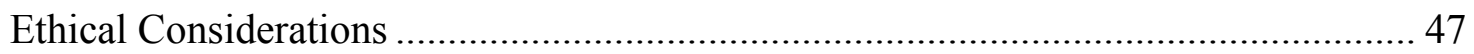

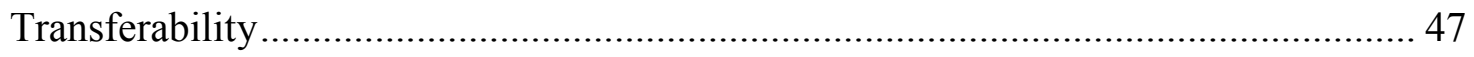

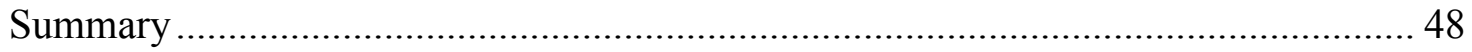

CHAPTER FOUR: SUMMARY OF RESEARCH FINDINGS ................................ 49

Theoretical Framework ..................................................................................... 50

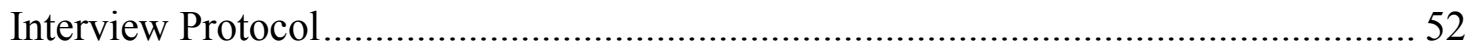

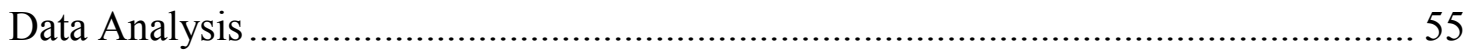

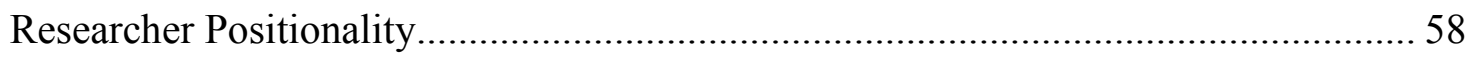

Impact of Out of School Suspension on Academic Motivation ............................... 61

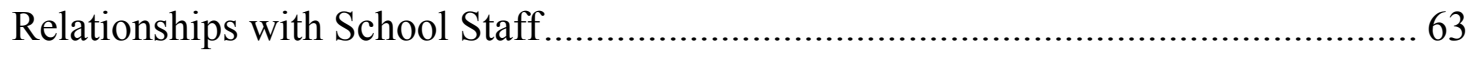

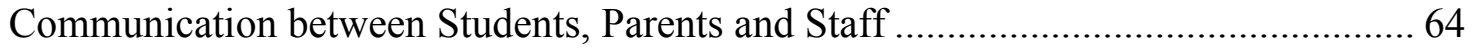

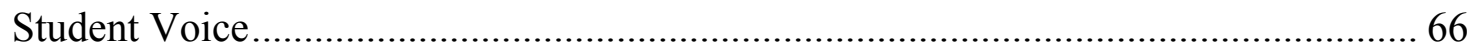

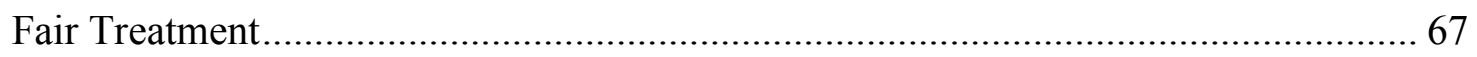

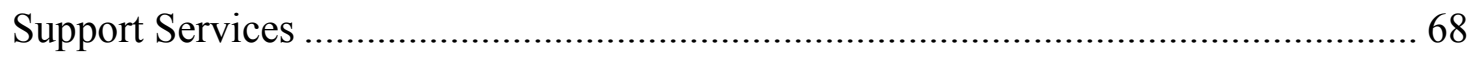

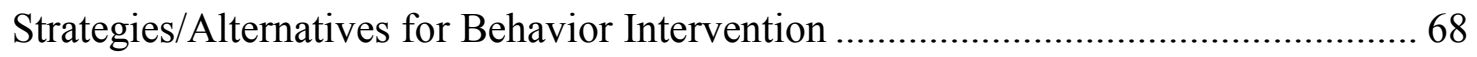

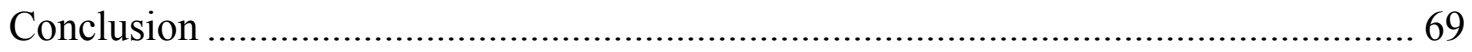


CHAPTER FIVE: SUMMARY, CONCLUSIONS, AND RECOMMENDATIONS ..... 71

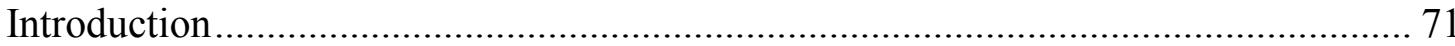

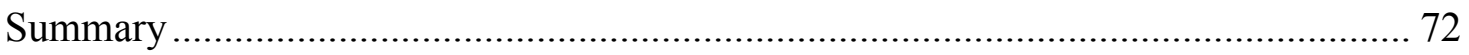

Discussion of the Results in Relation to the Literature ............................................. 73

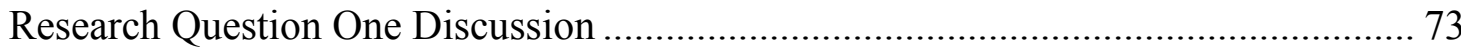

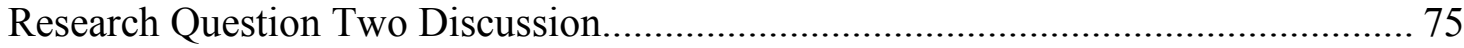

Research Question Three Discussion................................................................. 77

Implications for School Leaders ..................................................................... 78

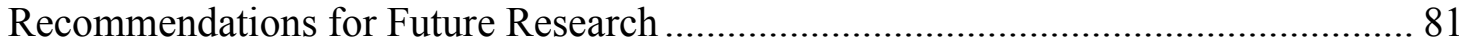

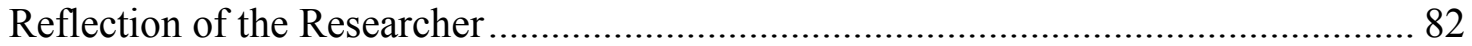

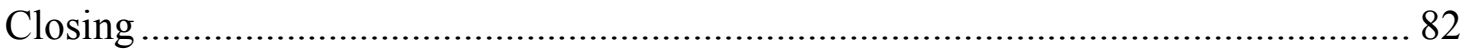

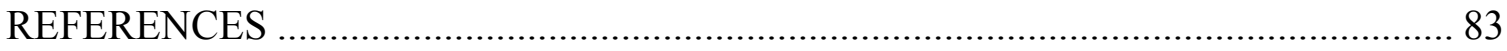

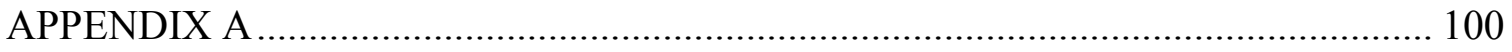

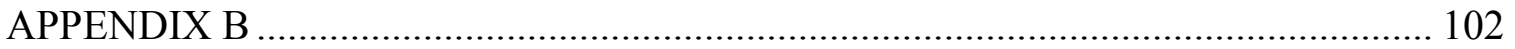

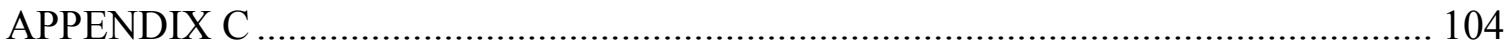

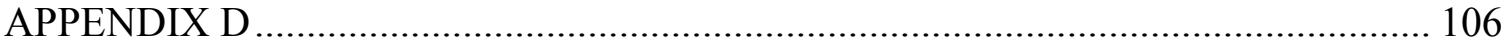

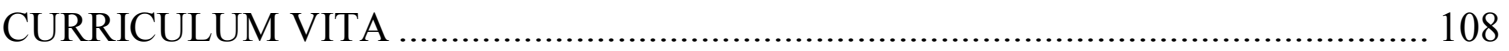




\section{CHAPTER ONE: INTRODUCTION TO THE PROBLEM}

Nearly 3.5 million public school students were suspended at least once in 20112012, adding up to 18 million instructional days lost in one school year (Skiba \& Losen, 2015). As Durkheim (1973) clarified long ago, the foundation of effective discipline lies in the achievement of "moral authority" based on trust, affirmation, and caring relationships. According to Hirschfield (2008), there has been a preponderance of antiviolence policies across many school districts which has created what has been called the "New American School", an environment of social control and fear that is more like a prison environment. This is particularly true of secondary urban schools.

In the 1980's, the term “Zero Tolerance” grew out of federal drug policy. Zero tolerance was intended primarily as a method of using severe and invariant consequences to send a message that certain behaviors would not be tolerated. According to Skiba \& Losen (2016), beginning in the late 1980s, fear of increased violence in schools led school districts throughout the country to promote zero-tolerance policies, calling for expulsion for guns and all weapons, drugs, and gang-related activity, and to mandate increased suspension and expulsion for less serious offenses such as school disruption, smoking, and dress code violations.

Exclusionary discipline may lead to poor academic outcomes for the student, an increased likelihood of dropping out of school, and an introduction to the criminal justice system (Cueller \& Markowitz, 2015). Students who have been suspended are three times

more likely to drop out of school than their peers (Ekstrom et al., 1986; Raffaele Mendez, 
2003; Wehlage \& Rutter, 1986). Being suspended from school also increases the chances a student will feel disconnected, intensify conflict with adults, and impact a youth's choice to engage in criminal activities (Skiba, Reynolds, Graham, Sheras, Conoley, Garcia-Vazquez, \& Edmiston,2006). Researchers have concluded that suspension is also a predictor of future suspensions, not a deterrent (Rafaele \& Mendez, 2003). Use of suspension is associated with lower academic achievement, an increased risk of deviant behavior and impacts on time graduation (Skiba \& Losen, 2015). When students experience out of school suspension and then return to school, many feel they cannot catch back up to their peers. This may be the final straw as a student struggles to decide whether they should drop out of school (Bloomberg, 2004).

In a study focusing on students with a history of school suspension and their journey to college success, there were three factors that contributed to student success: sense of belonging, family/home/school support, and strength of relationships (Banner, Hewitt, Kirkman, Mcnees \& Stickl, 2016). Students reported that their sense of belonging had a tremendous impact on how they handled their suspension. Relationships with staff and peers in the school also played a role in how suspensions were perceived and handled by the students. The stronger the relationships were, the more connected the students felt which increased their sense of belonging and connectedness to their school community. All students in the study felt that out of school suspension was an ineffective way to change behaviors (Banner, Hewitt, Kirkman, Mcnees \& Stickl, 2016). The goal of exclusionary discipline is to remove the offending student from the educational environment, thus promoting a safe environment for students (Lamont, J. H., Devore, C. D., Allison, M., Ancona, R., Barnett, S. E., Gunther, R., \& Young, T. 2013). Schools 
with higher rates of suspension have lower ratings of school safety based on student input and lead to a significantly poorer school climate (Skiba \& Losen, 2015). The implementation of school wide positive behavior intervention programs has shown much success in reducing school violence or disruption to the educational environment and improving overall school climate (Lamont et al. 2013). In 1998, a 12- year old boy was suspended from school in Chicago for writing gang-related symbols in his notebook. While suspended from school, he was shot and killed by two teens. This tragic event made some community members question whether suspension was the best consequence for this behavior. "A local priest, Father Bruce Wellems, of the Holy Cross Church, which is across the street from the school that the 12 year old attended said, "With something like zero-tolerance, you're not dealing with the problem...It's like the Ten Commandments-'Thou shalt not, thou shalt not...' OK, but what will you do? What's the other side of that?" (Ayers, Dohrn \& Jackson, 2001, p.11). If zero tolerance had not been the mandate, there may have been a different outcome for this student, such as keeping the student in school and providing interventions to help with the issues the young student may have been experiencing.

Research examining demographic correlates of school discipline exposure have concluded overwhelmingly that black students are disciplined more extensively than white students. This trend includes suspensions, discipline referrals, and expulsions (Krezmien, Leone \& Achilles, 2006; Losen, Hodson, Keith, Morrison, \& Belway, 2015; Porowski, O'Connor, \& Passa, 2014; Skiba, R. J., Horner, Chung, Rausch, M. K., May \& Tobin, 2011; Smith \& Harper, 2015; Vincent, Swain-Bradway, Tobin \& May, 2011; Wallace, Goodkind, Wallace \& Bachman, 2008). According to Mendez \& Knoff (2003), 
most suspensions for black males are for relatively minor violations such as disobedience. Discipline can create an inequitable setting within the school walls, students' minds and teachers' minds. Triplett, Allen, \& Lewis, (2014) found that school discipline has emerged as a critical arena in the quest for racial equity in education as a growing body of literature demonstrates that urban students of color are disproportionately subjected to punitive discipline as a result of zero tolerance policies. These factors also correlate to future delinquency and substance abuse for these students. There is evidence of disproportionality in the use of exclusionary discipline based on student characteristics.

Out of school suspension fall more heavily on historically disadvantaged groups, especially black students (Skiba \& Losen, 2015). African American students can expect to be suspended three and a half times more often for extended days at a time, for lesser offenses than their white peers (Smith, 2015; Rausch \& Skiba, 2004). The U. S. Department of Education's Office for Civil Rights caused a stir in 2014 when it released data showing that black students are suspended at three times the rate of white students. Sophisticated statistical models have consistently displayed that race continues to be a significant predictor of school exclusion even when controlling for poverty (Skiba \& Losen, 2015).

For students already experiencing major home-life stresses, out-of-school suspension provides yet another life stressor that, when compounded with what is already occurring in their lives, may predispose them to even higher risks of behavioral problems (Taras, Frankowski, McGrath, \& Mears, 2003; Skiba, Arredondo \& Rausch, 2014). Suspended students often already perform poorly academically and suffer greatly when 
they are away from the classroom. Professional associations such as the Kessel \& Norman Anderson American Psychological Association (2008) and Lamont, J. H., Devore, C. D., Allison, M., Ancona, R., Barnett, S. E., Gunther, R., \& Young, in the Journal of Pediatrics (2013), have issued reports on the ineffectiveness of and risks associated with disciplinary exclusion and have recommended the use of such exclusionary measures only as a last resort (Skiba, Arredondo, \& Rausch, M. K., 2014).

Fabelo, Thompson, Plotkin, Carmichael, Marchbanks, \& Booth, (2011), as part of the council of state governments' report, found that suspension for a discretionary school violation, such as dress code violation, nearly tripled a student's likelihood of involvement with the juvenile justice system within the subsequent year. Students who have experienced out-of-school suspension are more than eight times as likely to be incarcerated as those who graduate from high school (Castillo, 2013) and are ten times more likely to drop out of school (Lamont, J. H. et al, 2013). For a large number of atrisk youths, being suspended leads to other problems outside of school, increases the likelihood of receiving additional out-of-school suspensions (OSS) and may result in dropping out of school (Breunlin, D., et al. 2002; Craun, Dupper, \& Theriot, 2009).

Dropping out of high school leads to long-term fiscal consequences to the student and society as a whole. According to Lamont et al, (2013), students who do not graduate in four years or at all are a societal problem strongly associated with higher rates of incarceration and higher unemployment rates, costing taxpayers billions of dollars. A high school drop-out will earn $\$ 400,000$ (\$485,000 for males) less than a graduate over a lifetime, pay $\$ 60,000$ less in taxes and have a life expectancy that is six to nine years shorter than a high school graduate (Lamont et al,2013). 


\section{Purpose of the Study}

This study seeks to answer the following research questions:

Research question 1: How do students perceive out of school suspensions' impact on their academic motivation?

Research question 2: Do their perceptions change based on the severity of the offense(s)?

Research question 3: Is there a connection to the culture of the school community and out of school suspension?

By answering these questions, I seek to identify a relationship between student perception of the ways in which extended days of out of school suspension influence academic motivation. Further, does this student perception change based on the severity of the offense? Finally, I will examine whether or not there is a connection between the culture of the school community and out of school suspension. There are major implications for school policy and practice in this study. Disciplinary policies reflective of restorative practice and not exclusionary practice (except major offenses such as bringing a weapon to school) could be developed and implemented based on research outcomes. Additionally, school culture and climate could be positively affected though the implementation of school wide positive behavior intervention programs.

\section{Conceptual Framework}

\section{Scope of the study}

Within the social theory framework, the type of research I will use will be phenomenological research. Phenomenological research is a design of inquiry coming from philosophy and psychology in which the researcher describes participants' experiences and significant statements about a phenomenon. The focus is on how 
someone comes to understand the world, the essence of one's perceptions and experience with certain phenomenon (Glesne, 2016, p. 290).

The social aspect of my research lends itself well to the use of phenomenology because my research describes the lived experiences of individuals about a phenomenon as described by participants during individual interviews (Creswell, 2014). Schools are social institutions where students all come with a different story. School success involves more than academic performance. School is part of a student's existence and most of the time they are defined by what is observed by other students and teachers. This is why the relationships formed by students and teachers are important to their success.

The sample size for this research study is 16 subjects, 8 per school. Individual interviews will be conducted with students to identify perceptions about out of school suspension and the impact on academic motivation. Participants in this research study will be audiotaped during the interviews. Every effort will be made to make the participants comfortable and the location private. The researcher will meet with students in a secluded area of the building. Refreshments will be available for the participants.

Semi-structured questions were developed to create an open response type setting (Appendix A). Recorded verbatim responses will be transcribed. Student participants will share their experiences through responses to semi-structured questions. Semistructured questions help to define the areas to be explored, but also allows the participant to diverge from the question in order to pursue an idea or response in more detail.

\section{Key Terms}

Out of School Suspension- the removal of a student from the school environment for a designated amount of time for a behavior infraction. The number of days a student is 
suspended is based on the severity of the offense using a progressive behavior scale provided by the district.

Zero Tolerance - the policy of applying laws or penalties to even minor infringements of a code in order to reinforce its overall importance (Dictionary, C. E. 2014).

Juvenile Delinquency - the habitual committing of criminal acts or offenses by a young person, especially one below the age at which ordinary criminal prosecution is possible.

Academic Achievement- determining whether or not a student is successful in mastering academic standards and content using Standardized test scores and grade point averages Out-of-school suspension/ Exclusionary discipline- the removal of a student from the school environment for committing identified behavior offenses. These terms will be used interchangeably throughout the study.

Restorative Justice - a disciplinary approach that focuses on restoring relationships and repairing harm and developing students' social and emotional competencies (Morrison, 2003).

Positive Behavior Intervention and Support Approach - This approach focuses on changes that can be made for future success, not fixing a student's past. It is based on three main components: (1) Prevention; (2) Multi-tiered support; and (3) Data based decision making.

SES - socioeconomic status categorized as households with low, medium, and high income. Students with low income households usually qualify for fee waiver which pays for school class fees and books, school lunch, and college application charges. 


\section{Limitations to the Study}

The researcher has to identify personal biases, values, and personal background such as history, gender, culture, and socio-economic status (SES) that shape the interpretations formed during a study (Creswell, 2014). This study was conducted at one "point in time" and not over a period of time. This may have an impact on motivation and could be grounds for a future study.

\section{Sample Population}

Students will be selected from grades ten, eleven, and twelve. At each high school, the students will be broken down into two categories, lesser offenses and greater offenses. There will be four students per category for a total of eight students per school, 16 student participants in total. The first category will consist of four students who have been suspended for six or more days for level three (less severe) events. Level three interventions involve the short term (one to three days) removal of a student from the school environment because of the severity of the behavior. The short term suspensions may be appropriate when interventions and supports have been put in place but repeated offenses are still occurring. According to the Student Support and Intervention Handbook (2016) for the school district of this study, these events include leaving school grounds without permission, (unless in a school approved program that requires leaving school grounds) intentionally throwing an object that could potentially cause a disturbance or injury, failure to respond to questions or requests, and inciting a fight at school.

The second category will consist of four students who have been identified as having been suspended out of school for six or more days for level four (severe) events. Level four interventions involve the removal of the student from the school 
environment due to the severity of the behavior long-term (six to ten days). Long-term suspensions are used when student's behavior is jeopardizing the safety of others in the school. According to the Student Support and Intervention Handbook (2016) for the school district of this study, these events include physically fighting, direct profanity to an adult, robbery, sexual assault, and bringing a deadly weapon to school.

\section{Organization of the Study}

This study is organized as follows: Chapter 1 includes the introduction, statement of the problem, purpose of the study, scope of the study, key terms, data collection, previous studies, and limitations to the study. Chapter 2 reviews the history of school discipline, the school's role and responsibility in out of school suspensions, and who gets suspended and why. Chapter 2 also reviews how out of school suspensions affect educational outcomes and some alternatives to out of school suspension. Chapter 3 is an explanation of the research methodology used, data collection, and procedures of this study. Chapter 4 presents the descriptive narrative of the study's results and an analysis of the data. Chapter 5 summarizes the study's major findings and includes recommendations for future research and policy implications. 


\section{CHAPTER TWO: LITERATURE REVIEW}

\section{Introduction}

Current research has identified many factors that contribute to dropping out of school before high school graduation (Cook, Gottfredson, \& Na, 2010; Suh, Suh, \& Houston, 2007). One factor that has been identified as associated with higher school drop-outs is out-of-school suspension (Cook et al, 2010). School suspension, or exclusionary discipline, more than any other factor, has been shown to have the greatest detrimental impact on student educational outcomes (Cobb-Clark, Kassenboehmer, Le, McVicar, \& Zhang, 2015). Being removed from the school environment may have a negative impact on a student's connection to the school, increase alienation, damage relationships with adults, and increase youth's decisions to participate in delinquent behavior (Skiba et al., 2006). Disciplinary policies that remove rule-violating students from the learning environment have become a fixture of public education, with suspension rates doubling since the 1970s (Losen, 2011). Excessive use of exclusionary punishment in public schools has collateral consequences for the academic success of all students. Perry \& Morris (2014) theorized that exclusionary discipline policies have indirect adverse effects on non-suspended students in schools. The study examined the effect of suspension on reading and math achievement. Multilevel methods were used qualitative for interviews and observations, quantitative for MAP (measure of academic progress) testing data analysis, and data was collected using the Kentucky School 
Discipline Study (KSDS) - de-identified school records and supplementary data collected routinely from parents. Based on the findings of this study, the academic success of all students may be jeopardized if attending schools with excessively punitive discipline policies.

For the first half of the twentieth century, the U.S. incarceration rate was comparatively low and stable (Western, 2006). However, after policy analysts concluded that rehabilitation programs for offenders were largely ineffective (Lipton, Martinson, \& Wilks, 1975), public policy toward crime and social control shifted. In the 1980s, this new stance sparked a range of "get tough" approaches to crime control. Policies such as mandatory minimum sentencing, three strikes laws, and zero tolerance policing emerged from the assumption that more stringent criminal justice would reduce crime and enhance safety. This thinking marked a pivot toward punitive and exclusionary means of social control. Current school discipline practices are far more invasive and punitive than in past decades, reflecting a growing crime control approach to student misbehavior (Hirschfield, 2010).

In order to further investigate the issues identified, this study will address the following research questions: How do students perceive out of school suspensions' impact on their academic motivation? Do their perceptions change based on the severity of the offense(s)? Is there a connection to the culture of the school community and out of school suspension?

\section{History of School Discipline}

School suspensions and expulsions are the most commonly used form of discipline in K-12 schools, and their use has increased substantially since the advent of zero tolerance (Skiba \& Peterson, 2003). Zero tolerance is a term used to describe rigid, 
mandated-response approaches to school discipline (Bechtold, Cauffman, Monahan \& VanDerhei, 2014). The Zero Tolerance Task Force (Skiba et al, (2006) of the American Psychological Association (2006) determined that schools with higher suspension rates tend to have lower academic achievement, less focus on creating a positive school climate (social, cultural, academic, ethical), and receive lower ratings on school governance measures. According to the American Academy of Pediatrics Council on School Health, (Lamont et al, 2013), zero-tolerance legislation was prompted by violent acts perpetrated by white students, yet most of the out of school suspension occurring with zero-tolerance policy applications involve black or Hispanic students. A zerotolerance policy that mandates a meeting to address the offense allows school boards and administrators' flexibility in dealing with major infractions. However, a policy that mandates a particular consequence and leaves no consideration for extenuating circumstances ties the hands of school leaders and authorities. Some schools may not want the flexibility in the disciplinary consequence because they feel this sends the message that policy is the safest decision for the staff and students. However, "research indicates a negative relationship between the use of suspension and expulsion and schoolwide academic achievement, even when controlling for demographics such as socioeconomic status" (American Academy of Pediatrics Council on School Health, 2013). Aggressive exclusionary policies could end up harming the students these policies were designed to protect. "Problems with fairness, impartiality, uniformity, and flexibility have caused the effectiveness, validity, and justification of zero-tolerance policies to be questioned" (American Academy of Pediatrics Council on School Health, 2013). 
Over the past 30 years, sociologists have identified a profound shift in U.S. society toward an emphasis on crime, punishment, and social control. This "culture of control" has heightened the fear of crime, increased the desire for retribution, and expanded the scope of social exclusion (Garland, 2001). Control-oriented approaches to crime are exemplified by policies like the War on Drugs campaign and three strikes laws. Such policies have contributed to a four-fold increase in U.S. incarceration rates since the 1970s, resulting in the mass incarceration of millions of people (Western, 2006). As a way to "get tough" on crime, school zero tolerance policies grew from the drug enforcement policies developed in the 1980's by law enforcement officials. According to Hirschfield (2008), there has been such a preponderance of anti-violence policies across many school districts which has created what has been called the "New American School", an environment of social control and fear that is more like a prison environment. This is particularly true of secondary urban schools. United States school districts and the juvenile justice system were never intended to work together. However, over the past 30 years this has been the paradigm shift developed through a harmful framework, to the detriment of many vulnerable students and families. This phenomenon is often referred to as the "school-to-prison-pipeline" (Kang-Brown, Trone, Fratello, \& Daftary-Kapur, 2013).

School zero tolerance policies were developed to deal with offenses such as drug possession, gang activity, and possession of weapons. Over time, schools began using zero tolerance on lesser offenses such as tobacco use and school disruption (Allman \& Slate, 2011). Since the onset of zero tolerance, less severe behavior has resulted in higher rates of suspension which has led to questions and criticism of zero tolerance policies. 
Recent studies on exclusionary discipline find that the majority of the out of school suspensions are for minor offenses (Fabelo, Thompson, Plotkin, Carmichael, Marchbanks \& Booth, 2011; Losen \& Martinez, 2013). Based on school year 2009-2010, federal data confirms that middle and high school students are being suspended out of school for minor offenses, even though exclusionary discipline policies used on students who have a positive view of school may actually serve to disengage them and place them at risk for poor adaptation (Morrison et al., 2001). These policies do not take into consideration why events occur, what the reasons for the student's involvement are, and any history which may have attributed to the behavior (Kang-Brown et al., 2013; Skiba, 2000). A wider network of good students are being caught in the web of suspensions which could lead to students perceiving they are being betrayed by school staff. This may manifest in greater behavioral issues in the future. As a result of this, alternatives to exclusionary discipline are becoming a growing focus (Baker-Smith \& LipSchultz, 2016).

One unintended consequence of zero tolerance policies is that students who violate school rules and are suspended or expelled have an increased risk for contact with the juvenile justice system (Bechtold et al, 2014). When students are suspended out of school, there is often no adult supervision at home, resulting in an increased opportunity to engage in crimes in the community (Cuellar \& Markowitz, 2015). Routine Activity Theory is an environmental theory of crime. There are three criteria that have to be met before a crime is committed: (1) A motivated offender (2) a suitable target, and (3) 
absence of a capable guardian (Bechtold et al, 2014).

Figure 1:

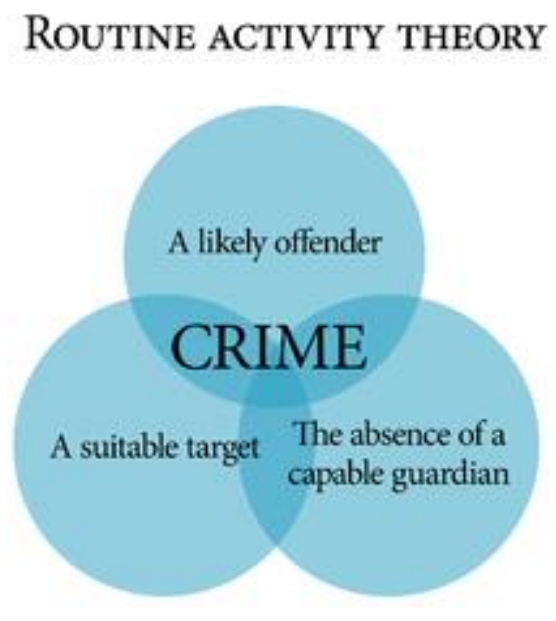

Physical convergence in time and space

A graphical model of the Routine
activity theory. The theory
stipulates three necessary conditions
for most crime; a likely offender, a
suitable target, and the absence of a
capable guardian, coming together
in time and space. The lack of any
of the three elements is sufficient to
prevent a crime which requires
offender-victim contact (Kohen \&
Felson, 2016)

\section{Ensuring Safety and Learning}

No two schools are exactly alike and disciplinary policies differentiate based on school size, location, and demographic makeup (Arum, 2003; Kupchik \& Monahan, 2006). School discipline is a balancing act. School administrators have to take into consideration many factors: trying to create a safe environment while maintaining a welcoming climate; treating students equitably and recognizing circumstances that influence behavior; and convincing students with behavior issues to correct their behavior while trying not to interrupt the learning taking place in the classroom (Barrett, McEachin, Mills, \& Valant, 2017). Getting discipline right is a very important characteristic of a good school. There are many instances where getting discipline wrong is a recipe for disaster (Barrett et al. 2017). School leaders have a legal obligation to keep schools safe.

Schools are mandated by the No Child Left Behind Act of 2001 to develop disciplinary policies and codes of conduct (Fenning, Pulaski, Gomez, Morello, McArdle, 
Morello, et al. 2012). These policies are to describe the responsibilities of all students and the consequences when behavior violations occur. Schools that follow a zero tolerance policy have been criticized by the Committee on School Health (2003) for using a onepunishment-fits-all approach. School officials have an ethical obligation to examine the consequences of their actions and, if necessary, make changes in policy and practice (Stader, 2004).

School districts create codes of conduct that students are expected to follow and unacceptable behaviors should be minimized and discouraged. Many schools choose to address these unacceptable behaviors by using out-of-school suspensions. School suspension is in fact the most commonly used form of discipline (Skiba \& Peterson, 2003) and the use of suspension and expulsion has increased substantially since the advent of zero tolerance policies (Skiba \& Peterson, 2003). The choice to suspend and for how long is up to the school for most offenses. Instead of relying so heavily on the exclusionary measure of an out of school suspension, high schools need discipline practices that improve long term student outcomes (Flannery, Fenning, Kato \& McIntosh, 2014).

Student misbehavior will occur. It is the responsibility of educators to respond to misbehavior in a timely fashion, appropriate manner, and use an education framework as an opportunity to teach coping strategies and replacement behaviors. It is the school's responsibility to implement programs to help decrease the frequency and intensity of misbehavior for individual students and the entire student body. Despite preventive efforts, there will be circumstances in which suspension is warranted for the safety of students and staff (Noltemeyer, Ward, \& McLoughlin, 2015). 
Traditionally, the goal for exclusionary discipline was to remove the offending student from the educational environment, thus promoting a safe environment for students (Lamont, Devore, Allison, Ancona, Barnett, Gunther, \& Young 2013). Schools with higher rates of suspension have lower ratings of school safety based on student input and lead to a significantly poorer school climate (Skiba \& Losen, 2015). Nearly 3.5 million public school students were suspended at least once in 2011-2012, adding up to 18 million instructional days lost in one school year (Skiba \& Losen, 2015). The implementation of school wide positive behavior intervention programs have shown much success in reducing school violence or disruption to the educational environment and improving overall school climate (Lamont, Devore, Allison, Ancona, Barnett, S Gunther \& Young, 2013).

Contrary to the proposed benefits of "getting tough on crime," research in criminology documents devastating consequences for offenders, families, and communities. These "collateral consequences" reveal the hidden costs of highly authoritarian approaches to social control (Mauer \& Chesney-Lind, 2002). In the U.S. education system, this criminological perspective is conceptualized in the exclusionary discipline practices as a manifestation of the culture of control in schools. Survey data from a study of all of Chicago's schools found that the relationships developed between parents, teachers, and students was a much better predictor of feelings of safety (Skiba \& Losen, 2015). 


\section{Suspendable Offenses}

\section{Factors Associated With Suspensions}

The choice to suspend and for how long is up to educational leaders at the school for for most offenses in alignment with district provided codes of conduct. According to the Code of Conduct manuals for several urban school districts, there are a variety of disciplinary policies regarding out of school suspension. These districts most often use a progressive discipline process which allows students the opportunity to make mistakes, learn from them, and support to change their behavior over time. If the behavior does not change using the lowest identified level of intervention, a harsher consequence is given. In a review of sample policies from large urban school districts, there were several similarities: the number of days suspended depends on the severity of the offense; suspensions are broken down into two categories based on the offense; lesser offenses such as leaving class without permission, horseplay, and unexcused tardiness/nonattendance to class receive one to three out-of-school suspension days; greater offenses such as fighting, bringing weapons to school, and harassment receive up to six out-of-school suspension days and alternative placement in another educational facility is sometimes recommended. Unless the offense is blatant and clear-cut, it is up to the suspending administrator to decide the seriousness of the offense. In a study done of suspensions and achievement that spanned three years, Arcia (2006) found that, prior to suspension, students who received the highest number of out of school suspension days had lower achievement levels than students who receive fewer or no suspension days.

\section{Race}

A student's race, class, and disability can predict whether that student is likely to be suspended or expelled, which suggests that some disciplinary infractions are not 
merited by a student's conduct (Gowdey, 2015). Urban schools, where students are usually more culturally diverse and tend to come from low socioeconomic (SES) backgrounds, have the most suspensions, but students with lower SES backgrounds' experience suspension more often in all schools (Arcia, 2006; Rausch, Skiba, 2004). There is evidence of disproportionality in the use of exclusionary discipline based on student characteristics. Out of school suspensions fall more heavily on historically disadvantaged groups, especially black students (Skiba \&Losen, 2015). African American students can expect to be suspended three and a half times more often for extended days at a time, for lesser offenses than their white peers (Smith, 2015; Rausch \& Skiba, 2004). The U. S. Department of Education's Office for Civil Rights caused a stir in 2014 when it released data showing that black students are suspended at three times the rate of white students. Sophisticated statistical models have consistently displayed that race continues to be a significant predictor of school exclusion even when controlling for poverty (Skiba \& Losen, 2015).

Research examining demographic correlates and school discipline exposure have concluded overwhelmingly that black students are disciplined more extensively than white students. This trend includes suspensions, discipline referrals, and expulsions (Krezmien, Leone \& Achilles, 2006; Losen, Hodson, Keith, Morrison, \& Belway, 2015; Porowski, O'Connor, \& Passa, 2014; Skiba et al., 2011; Smith \& Harper, 2015; Vincent, Swain-Bradway, Tobin \& May, 2011; Wallace, Goodkind, Wallace \& Bachman, 2008). According to the Mendez \& Knoff (2003) most suspensions for black males are for relatively minor violations such as disobedience. 
According to Arcia (2009), school disciplinary policies can negatively impact the success of African American children, especially African American males who have the highest rate of suspensions. Psychosocial risks to vulnerable students may be increased due to them feeling that they are not part of the school community (Cameron \& Sheppard, 2006). Suspensions can cause harm to families when parents may have to miss work to tend to their suspended child by meeting with school officials. This also damages the school-family relationship critical to academic success (Epstein, Galindo, \& Sheldon, 2011; Losen, 2011; Semeke, Grabacz, Kwon, Sheridan, \& Woods, 2010).

In a study by Gibson and Haight (2013), oral narratives were used as the lens to better understand the cultural meanings of suspensions for caregivers of African American children. This research was conducted in Minnesota, which was one of the states with the highest rates of suspension in school year 2007-2008 (Losen, 2011), with black children three and a half times more likely to be suspended than white children (Cornell, Allen, \& Fan 2012). Caregivers in this study characterized out of school suspensions as morally problematic and described them as disproportionate, unfair, undeserved, or inappropriate for their child's offense (Gibson \& Haight, 2013). Caregivers in this study shared that suspensions may reward student's inappropriate behavior. As one caregiver explained, “I don't like suspensions because to me it sends false information to a child. It says, 'If I act up and act out, I'm gonna get to leave school. And I get to hang out at home.' And that's not a good message for the kids." (Gibson \& Haight, 2013). 


\section{Gender}

Gender plays a role in the disproportionality of disciplinary practices, as black males are six times more likely to be suspended than white females (Gregory, 1997). In a demographic analysis of schools and disciplinary infractions in a large school district, males (when compared to females), and black students, (when compared to White and Hispanic students), are at a much higher risk for being suspended. This is not new information as it has been reported many times before in research findings (Costenbader \& Markson, 1998; Dupper \& Bosch, 1996). The analysis also showed that black girls are at greater increased risk than White or Hispanic girls to be suspended. A study conducted by Anil and Jordan (2009) tested the hypothesis that the odds of a student being referred for disciplinary action increase if the student is male, black, in special education classes, or poor. This research was conducted with eighth grade students at four middle schools in a rural/suburban school district in Georgia. This grade was chosen because nationally, $35 \%$ of students who drop-out of school do so between the 9 th and 10th grades (the legal drop out age in most states). Thus, it is in the transition from middle to high school (beginning in eighth grade) that students are making educational choices. The researchers found that discipline is being disproportionately applied with respect to blacks, particularly boys, and especially students who are poor (Jordan \& Anil, 2009).

\section{Students with Disabilities}

Students with disabilities are suspended at a rate of nearly twice that of students without disabilities and are removed for longer periods of time, even when controlling for poverty (Skiba \& Losen, 2015). Nationally, one out of every three black male secondary school students with disabilities was suspended out of school at least one time for school 
year 2009-2010 (Losen \& Martinez, 2013). Disparities generated by harsh school discipline policies extend to students with disabilities. These students are suspended about twice as often as their non-disabled peers. Researchers estimate one in four black students with disabilities were suspended at least once in the 2009-2010 school year. These disparities continue into the juvenile justice system, where empirical studies have consistently found disability prevalence rates many times greater than in school populations (Gowdey, 2015). Research also shows that black students are placed in more restrictive educational settings than white students diagnosed with the same disability. At the national level, rates of restrictive placements for disabled minority students appear greater than disabled white students; however, the restrictive placements may actually be even more severe in large, urban school districts serving predominantly minority and low-income populations (Gowdey, 2015).

\section{Suspension rates by school type}

Suspension rates rise dramatically in the middle school grades compared to elementary school grades (Bergquist, Bigbie, Groves \& Richardson, 2004; Mendez \& Knoff, 2003). The rate of suspension peaks in sixth grade with rates five times greater than in fifth grade, which generally correlates to greater chances for out of school suspensions in high school (Arcia, 2006). Nationally, the likelihood a student will be suspended out of school increases from $2.4 \%$ in elementary to $11 \%$ in middle school (Losen \& Martinez, 2013). At the secondary level students with disabilities are suspended nearly triple the number of students without disabilities (Losen \& Martinez, 2013). While far fewer students are suspended in elementary than in secondary school, black students are much more likely than their White or Hispanic peers to be suspended at the elementary level (Mendez \& Knoff, 2003). 


\section{Academic Achievement \\ Out of School Suspensions and Educational Outcomes}

Out of school suspension has a negative impact on student academic achievement and student engagement within the school community (Flynn, Lissy, Alicea, Tarzartes, \& McKay, 2016). Research indicates a negative relationship between the use of suspension and school-wide academic achievement, even when controlling other variables such as socioeconomic status (Lamont et al, 2013; Triplett, Allen, \& Lewis, 2014; American Academy of Pediatrics, 2013). Students who have experienced out-of-school suspension are more than eight times as likely to be incarcerated as those who graduate from high school (Castillo, 2013) and are ten times more likely to drop out of school (Lamont et al, 2013). For a large number of at-risk youths, being suspended leads to other problems outside of school, increases the likelihood of receiving additional out-of-school suspensions (OSS) and may result in dropping out of school (Dupper, Theriot, \& Craun, 2009; Breunlin, D., et al. 2002). Research shows that students who have a history of suspension, more than any other characteristic, causes the greatest negative consequence on student educational outcomes (Cobb-Clark, Kassenboehmer, Le, McVicar, \& Zhang, 2015).

For students already experiencing major home-life stresses, academic out-ofschool suspension provides yet another life stress that, when compounded with what is already occurring in their lives, may predispose them to even higher risks of behavioral

problems (Frankowski, McGrath, Mears, \& Taras, 2003; Skiba et al., 2014). Suspended students often already perform poorly academically and suffer greatly when they are away from the classroom. Professional associations such as the American Psychological 
Association (2008) and the American Academy of Pediatrics (2013) have issued reports on the ineffectiveness of and risks associated with disciplinary exclusion and have recommended the use of such measures only as a last resort (Skiba et al., 2014).

According to the research, higher suspending schools do not experience any gains in achievement. However, they do experience higher dropout rates and increase the risk that their students could become connected to the juvenile justice system (Balfanz, 2013; Fabelo, Thompson, Plotkin, Carmichael, Marchbanks, \& Booth, 2011; Shollenberger, 2013). Frequent use of suspensions also increases the risk of safety issues in the community and school because students become disengaged and the trust between students and adults is diminished (Finn \& Servoss, 2013; Steinberg, 2013). The overreliance on out of school suspensions when there are effective alternatives available is very costly to the economy and to the very fabric of democracy (Kupchik \& Catlaw, 2013; Marchbanks, Blake, Booth, Carmichael, Seibert \& Fabelo, 2013).

It is estimated that more than 1 million youth drop out of school each year and, even with reform efforts by educators and policymakers over the years, the graduation rate has hovered at around $75 \%$ for the past 45 years (Rumberger, 2011). Public inner city schools report that for each student who graduates there is a student who drops out. A disproportionate number of these students are Black and Hispanic (Knesting, 2008). Some studies show drop-out rates as high as $47 \%$ for Hispanics and $61 \%$ for Blacks, while Hispanics make up only $13 \%$ of the U.S. population and Blacks make up $12 \%$ of the total population (Knesting, 2008). Existing research in education shows that racial discrepancies in school punishment impact life trajectories negatively (Skiba et al. 2011). According to the 2014-2015 school year data, black males were reported to have the most 
suspension incidents across one large urban school district. The average per school suspension rates for black males was 146 suspension incidents. The average for white males was 71 . The next highest group for suspension incidents was black females at 91 per school with 35 per school for white females. Hispanic students had an average of 10 suspension incidents for males and 3 per school for females.

\section{Dropout Rate}

Dropping out of high school leads to long-term fiscal consequences to the student and society as a whole. According to the Council on School Health (2013), students who do not graduate from high school become a national problem that has social and economic implications for individuals and for society. A high school drop-out will earn an average of $\$ 400,000$ ( $\$ 485,000$ for males) less than a graduate over a lifetime and pay $\$ 60,000$ less in taxes and has a life expectancy that is six to nine years shorter than a high school graduate. Once a student drops out of school, it is very difficult to overcome barriers to come back to school and complete school successfully (Fenning, Pulaski, Gomez, Morello, McArdle, Morello, et al., 2011). Out of school suspensions correlate with an increased risk of involvement with the juvenile justice system and of dropping out of high school. This, in turn, increases the chances of arrest as an adult. Aside from the escalation of subsequent school discipline and its mutation into criminal justice referrals, even missing a few school days per year hurts a student's academic performance (Gowdey, 2015).

Sharkey and Fenning (2012) cited research showing that suspension is not only ineffective at deterring behavior infractions, but suspension is also connected to academic failure and school dropout. Instead of students learning from their mistakes, suspensions 
may result in counterproductive outcomes. There is limited research regarding the link between suspensions and detrimental outcomes. However, schools with high suspension rates often have lower mean scores on state achievement tests than schools with lower suspensions rates (Rausch \& Skiba, 2004). Even when black student enrollment and SES was controlled, suspension remained an impactful predictor of success on state achievement tests in both the elementary and secondary schools (Rausch \& Skiba, 2004).

There may be several factors impacting the relationship between suspension and academic achievement. The missed instruction due to suspension, disengagement from school, and preexisting behavioral or academic issues that caused the suspension can together influence achievement (Arcia, 2006). Students with a history of suspension have reduced graduation rates (Cobb-Clark, Kassenboehmer, Le, McVicar, \& Zhang, 2015). Arcia (2006) has linked suspended students with a lower reading rate when compared with students who have never been suspended and found that the more a student is suspended the more percentage points are lost in reading. Additionally, Noltemeyer, \& Mcloughlin , \& Ward, (2015) concluded that students with a history of suspension have lower rates of attending postsecondary institutions which impacts families and society as a whole.

\section{Alternatives to Out of School Suspension}

Research reveals negative associations between suspensions and academic outcomes. Research also reveals the important role that schools and districts have in ensuring that the educational environment is safe and conducive to learning. If out of school suspensions are problematic, other options have to be considered. To address this issue requires the use of a social theoretical framework. Schools are considered educational institutions but they are also socializing institutions. Though less explicit than 
the academic curriculum, the expectations, rules, and consequences that form the social curriculum of schools are no less important in determining school success (Skiba \& Peterson, 2003). One of the key tenets of social learning theory is that learning is not purely behavioral; it is a cognitive process that takes place in a social context. This can occur through observation or direct instruction. Learning can occur through the use of rewards or punishment.

In every school and classroom, there is a social curriculum. Teachers set their expectations through the use of classroom rules with explanations and consequences. Explanations of expectations are very important especially at the beginning of the school year. Teachers then reinforce these expectations from the feedback received based on positive or inappropriate behavior (Skiba \& Peterson, 2003). The majority of students come to school each day with the ability to recognize what is expected and acceptable. Most people recognize how unstated social rules change based on the situation and can adjust. For some students, this is not an automatic process due to the experiences they have encountered at home (Skiba \& Peterson, 2003). Beachum \& McCray (2011) warn about the consequences when schools do not take into consideration the culturallyspecific needs of black children. This makes it increasingly difficult in the school setting when this is seen as inappropriate behavior, which could lead to suspension. In short, teaching the social curriculum is utilizing the best resources and knowledge to teach children the behaviors they need to be successful in the classroom and in life (Skiba \& Peterson, 2003). Resources have to be available for schools to implement preventive programs to address behavior issues before they become safety and security issues. The culture and climate of schools depends on it. Policies affecting the codes of conduct for 
student behavior have to be examined and adjusted as needed to include positive behavior programs and restorative practices. According to Skiba \& Losen (2015), “A recent national initiative addressing disproportionality in school discipline has been the Discipline Disparities Research-to-Practice Collaborative, a group, educators of 26 nationally recognized researchers, educators, advocates, and policy analysts who came together to address the problem of disciplinary disparities" (p. 7). After three years of gathering relevant literature and meeting with stakeholders, the collaborative released four briefing papers on discipline disparities. The collaborative also had a concentration on increasing the availability of evidenced-based interventions. Resources to implement these programs, including professional development for staff, have to be made available. School leaders have to broaden their interest to include state and federal issues. State and federal levels of government are more involved now than ever in education policy (Fowler, 2013). Alternatives to using out-of-school suspensions have a more positive impact on the well-being and academic achievement of students. Successful implementation of effective prevention and intervention approaches develop positive behavior and keep students in constructive environments (Bruns, Moore, Stephan,Pruitt \& Weist, 2005; Skiba, R \& Peterson, R. 2003).

There are alternatives to exclusionary policies schools could utilize, and these alternatives are showing promise in reducing out of school suspensions. Educational leaders have shifted their focus to alternative models and practices in school discipline (Skiba \& Losen, 2015). There are resources available for schools to use as alternatives to out-of-school suspension. Many successful approaches involve six key steps: (1) Establish a foundation for collaboration or operation, (2) Build faculty involvement, (3) 
Establish a data-based decision making system, (4) Brainstorm and select strategies within an action planning process, (5) Implement school-wide program through an action plan (George., H., Harrower, J. \& Knoster, T., 2003).

Restorative Justice is a disciplinary approach that focuses on restoring relationships and repairing harm whiledeveloping student's social and emotional competencies (Morrison, 2003). Restorative Justice practices begin with a review of staff language. Staff language must move away from terms associated with criminal activity including crime, victim, offense, and punishment. It must embrace restorative language of violation, harm, and accountability. The focus moves away from punitive consequences to repair of property and restoration of relationships. Discipline decisions are made together with the harmed individuals and community members. A mediation/restorative circle can be used proactively to develop or reactively respond to conflicts. The circles give people an opportunity to share and listen to each other in a safe, equitable environment (Pranis, 2005). Student discipline practices in alignment with restorative justice move away from issuing sanctions to and against a student and toward sanctions occurring with and for students accompanied with school community members (Costello, Wachtel \& Wachtel, 2009). Staff members work to identify the harm, involve stakeholders, and ensure accountability because it is essential that students understand how behavior impacts the school community and their membership in the community is a priority.

In a study done at a high poverty school in Oakland, California, teachers are attributing a 51\% decrease in suspensions, a decline in teacher disrespect, and a safer school environment to the implementation of restorative justice. According to David 
Yusem, Program Manager of restorative justice for the Oakland Unified School District, the teacher or mediator asks non-judgmental, restorative questions such as "What happened? How did it happen? What can we do to make it right?" They discuss how the harm done can be repaired and develop a plan. The process is all about building and repairing relationships. The school uses a three-tiered approach of restorative justice. The first tier is preventive and involves using student restorative circles to share inner most feelings. The second tier is intervention where restorative practices are used to broken relationships. The third tier focuses on reentry to school after a student has been suspended, expelled, incarcerated or truant.

The social discipline window is a model for differentiating the practice of restorative justice from other forms of social regulation (Morrison, 2013). The social discipline window requires a balance of high levels of control/limit setting with high levels of support, nurturing and encouragement when using the restorative approach (Morrison, 2013).

Figure 2: Social Discipline Window

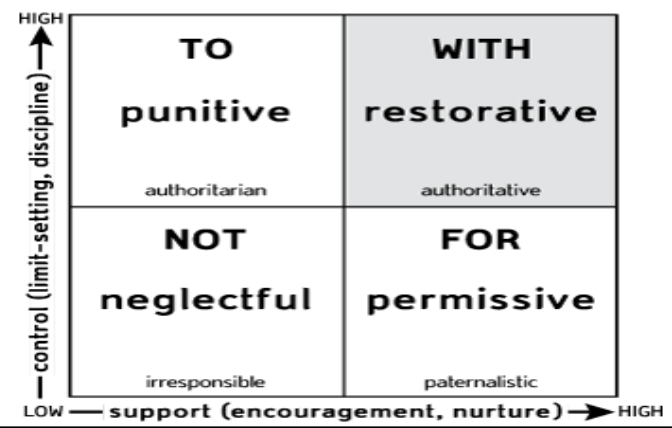

High control and Low support $=$ Punitive/Authoritarian Low control and low support $=$ Neglectful High support and low control $=$ Permissive High support and high control $=$ Restorative (Morrison, 2003) 
The first level targets all students in an effort to develop students' social and emotional competencies, especially in the area of resolving conflicts. Students are taught how to resolve conflicts in a respectful manner. The second level involves a wider audience when trying to resolve conflicts needing more attention that affect a greater number of individuals. The third (tertiary) level typically involves more serious issues where the parents, guardians, school officials or social workers may get involved. At each level, the principles of restorative justice are used with inclusive and respectful dialogue. As an example of a restorative program, PBIS uses restorative practices as its premise.

One promising program that has been extensively evaluated is the Consistency Management and Cooperative Discipline (CMCD). CMCD is a school-wide program designed to improve school discipline in inner-city schools. The Center for the Study of Violence Prevention at the University of Colorado reviewed 116 programs in the year 2000 and CMCD was one of only four U.S. programs that met their rigorous evaluation criteria (Dupper, Theriot, \& Craun, 2009). A core component of CMCD is designing a classroom where teachers and students work together to create the rules of the classroom. Positive behaviors become the focus and are rewarded. This empowers students and makes them accountable for the rules and class expectations they have created. CMCD has been evaluated primarily with African American and Latino students.

A trend in research on out of school suspension shows a dramatic emphasis on relationships being a key factor in what leads to students being suspended or not. The better the relationship is between students and teachers/staff members, the less likely students are to commit offenses that lead to suspension. Interventions that focus on strengthening teacher-student relationships can reduce the use of exclusionary discipline 
(Skiba \& Losen, 2016). This is shown in the use of restorative practices by schools where building positive relationships and trying to repair broken relationships is the focus. (Skiba \& Losen, 2016). School culture and climate improve when school wide positive behavior intervention programs are implemented.

One approach that many school districts have adopted is the Positive Behavior Intervention and Support (PBIS) approach. This approach focuses on changes that can be made for future success, not fixing a student's past. It is a based on three main components: (1) prevention; (2) multi-tiered support; and (3) data-based decision making. Prevention includes the whole school. Students are taught expected behaviors and provided support for success on a prevention-oriented basis (Flannery et al., 2014). Using a tiered level of support might include just a reminder for a minor infraction or a specific intervention for a bigger infraction. Some of the interventions might include: the development of a behavior contract, parent contact/intervention, community service, behavior monitoring, reeducating a student on acceptable behavior, and alternative programming. In a study done on the effects of PBIS on levels of individual student problem behaviors during a three year trial, results of a multilevel latent growth model showed statistically significant decreases in student office discipline referrals, with increases in comparison schools. The sample included 36, 653 students in twelve high schools. Eight high schools implemented PBIS and 4 schools were used as comparison schools (Flannery et al., 2014).

\section{Challenges for Implementation}

One challenge in the implementation of structures to improve student behavior is staff perception. Behavior perception is subjective. One staff member may determine that a student is disrespectful, yet another staff member may see the behavior as somewhat 
disruptive but not disrespectful. Staff members may also apply disciplinary consequences based on subjective criteria such as gender, ability status, or ethnicity. This subjective nature of behavior can cause supplemental issues with student perceptions of fairness and equity. This challenge must be addressed collectively with professional development and individually with coaching. All staff members must be vested in improving the school culture and climate with this preventative, restorative, and incentive based approach for behavior expectations and individualized behavior plans for students requiring Tier II and Tier III behavior support. Morrison (2003) cites that one limitation to a restorative approach to discipline is the challenge of long term utilization. Staff members become intolerant with misbehavior and lose patience with the process resulting in haphazard utilization of punishment and student counseling/coaching strategies. Teacher fidelity of implementation is essential for intervention success (Stormont et al., 2015). Classroom teachers will not be able to work in isolation as this can be a limitation as it requires a change of practice. This systems approach to behavior and school culture require collaboration, communication, consultation, and community learning. This may be a challenge due to the historically isolationist position of classroom teachers.

\section{Summary}

Until schools implement more positive behavior intervention approaches, disciplinary problems will continue. The motivation for students experiencing out of school suspensions will continue to decline. Consequences for the severity of offenses has to be adjusted due to students being suspended for minor offenses. These exclusionary practices occur disproportionately with African Americans and students from lower socioeconomic backgrounds. The use of exclusionary discipline increases the chances that students will experience poor academic performance and may make the 
choice to drop out of school. When students experience a history of out of school suspensions, this decreases their chances for attendance at a post- secondary institution. More research is needed on factors that identify the relationships between suspension and outcomes (Noltemeyer et al., 2015). 


\section{CHAPTER THREE: METHODOLOGY}

\section{Introduction}

This study seeks to answer the following questions: How do students perceive out of school suspensions' impact on their academic motivation? Do their perceptions change based on the severity of the offense(s)? Is there a connection to the culture of the school community and out of school suspension?

Constructivism is a perspective typically seen in qualitative research.

Constructivists believe that individuals seek understanding of the world in which they live and work. The researcher's job is to interpret the meanings others have about the world. Rather than starting with a theory, the researcher develops a theory or pattern of meaning. Crotty (1998) identified several Constructivist assumptions:

1) Human beings construct meanings as they engage with the world they are interpreting. Qualitative researchers tend to use open ended questions so views can be shared by participants. 2.) Humans engage with their world and try to understand it based on their perspectives. Qualitative researchers seek to understand the context of the participants by gathering information personally. They interpret what they find based on their own experiences and background. 3) The basic generation of meaning is always social, arising in and out of interaction with a human community. Qualitative research is largely inductive; the researcher generates meaning from the data collected in the field. 
It is the hope of this researcher that this study will help yield understanding about the impact of out of school suspensions on students. Student voice can help educators in the development of more effective school discipline policies. Creswell (2014) defines qualitative research as:

An approach for exploring and understanding the meaning individuals or groups ascribe to a social or human problem. The process of research involves emerging questions and procedures, data typically collected in the participants' setting, data analysis inductively building from particulars to general themes, and the researcher making interpretations of the meaning of the data (p. 4).

There are several types of qualitative inquiry a researcher may use. These include the following: Phenomenological (researcher describes the lived experiences of individuals about a phenomenon as described by participants), narrative (from the humanities in which the researcher studies the lives of individuals and asked one or more individuals to provide stories about their lives), ethnography (grounded in anthropology and sociology in which the researcher studies the common patterns of behaviors, language and actions of an intact cultural group in a natural setting over an extended period of time), and case study (researcher develops an in-depth analysis of a case, often an event, activity, program or one or more individuals). I propose to use a phenomenological inquiry design for my study. Individual interviews will be conducted with students to identify perceptions about out of school suspension and the impact on academic motivation. Further, I intend to seek an answer to whether the severity of the offense changes the perception of the impact on their academic motivation through the 
use of individual interviews using semi-structured interview questions. Finally, is there a connection between the culture of the school community and out of school suspension?

\section{Social Learning Theory}

In every school and classroom, there is an academic curriculum and a social curriculum. Teachers set their expectations through the use of classroom rules with explanations and consequences. Explanations of expectations are very important and need to be reinforced throughout the school year. Teachers then reinforce these expectations from the feedback received based on positive or inappropriate behavior (Skiba \& Peterson, 2003). In this chapter I will discuss social learning theory as my theoretical framework. I will also discuss the use of individual interviews and phenomenology and why these were chosen as the most effective venues to seek the information for this qualitative study. Additionally, I will address the reasons for this study from the initial interest to the anticipated outcomes will be discussed. I will share how the students were identified and placed in different categories. Furthermore, I will discuss the protocol for the interviews using semi-structured questions. I conclude with my process for collecting and analyzing my data from the interviews.

Themes will emerge and acceptable behavior will be displayed as a reference during the focus groups. The majority of students come to school each day with the ability to recognize what is expected and acceptable. Most individuals recognize how unstated social rules change based on the situation and can adjust. For some students, this is not an automatic process due to the experiences they have encountered at home (Skiba $\&$ Peterson, 2003). Out of school suspension may mean severe consequences at some homes but not others. Beachum and McCray (2011) warn about the consequences when schools do not take into consideration the culturally-specific needs of black children. This 
makes it increasingly difficult in the school setting when certain behavior is acceptable in the home but is seen as inappropriate at school. In short, teaching the social curriculum is utilizing the best resources and knowledge to teach children the behaviors they need to be successful in the classroom and in life (Skiba \& Peterson, 2003).

According to Skiba \& Peterson (2013), the Social Learning theory discusses how the social curriculum, expectations about social behavior, is less explicit than the academic curriculum; however, the rules, expectations and consequences are no less important than the academic curriculum (Skiba \& Peterson, 2003). One of the key tenets of social learning theory is that learning is not purely behavioral; rather, it is a cognitive process that takes place in a social context. This can occur through observation or direct instruction. Learning can occur through the use of rewards or punishment. Focusing on the use of out of school suspension as a consequence of negative school behavior, this study will seek to find out how out of school suspension is perceived by students. Some students may actually perceive it as a reward and not a punishment.

\section{Phenomenology}

Phenomenological research is a design of inquiry coming from philosophy and psychology in which the researcher describes participants' experiences and significant statements about a phenomenon. The focus is on how someone comes to understand the world, the essence of one's perceptions and experience with certain phenomenon (Glesne, 2015, p. 290). This design typically involves using interviews (Creswell, 2013, p.1) The first principle of analysis of phenomenological data is to use an emergent strategy, to allow the method of analysis to follow the nature of the data itself which may emerge or change in the course of analysis (Waters, 2017). To get at the essential meaning of the experience, a common approach is to abstract out the themes. This 
process is referred to as "the phenomenological reduction" which is a conscious awareness of the phenomenon as a phenomenon. The event is not an example of this or that theory but should be seen as a phenomenon in its own right, with its own meaning and structure. Anybody can hear words that are spoken; however, to listen for the meaning and emerging themes from the event as a whole is to have adopted an attitude of openness to the phenomenon in its inherent meaningfulness (Hycner, 1985). The researcher has to suspend their own meanings and interpretations and place themselves in the world of the individual being interviewed. It means trying to understand the meaning of what the person is saying rather than what the researcher expects the person to say. I am using phenomenology to abstract themes in order to get the perception of the experience of out of school suspension on academic motivation based on the responses by the participants.

\section{Context}

For this study, the largest urban school district in Kentucky will be used. According to the data books compiled by the district of the two high schools used for this study, one high school's, Aaron High School, 2017-2018 enrollment is 1,301 students, 34\% categorized as English as a Second Language Learners. This high school had the highest number of suspensions for school year 2016-2017 for a total of 963 suspensions in a district which includes 21 high schools. The dropout rate was also the highest in this district at 5.2\% for the 2015-2016 school year. Retention rate for 20152016 was $15.6 \%$ and for $2016-2017$ was $12.4 \%$, also the highest in the district. The adjusted cohort graduation rate for 2016-2017 was 73.3 and the free/reduced Lunch rate was 86.2 for 2015-2016. The second high school, Lucas High School, that will be used for this study has an enrollment of 749 students for 2017-2018 school year. The 
free/reduced lunch rate is 75.7\% for school year 2017-2018. Lucas High School had 552 suspensions for $2016-2017$ and the attendance rate was $85.6 \%$. The adjusted cohort graduation rate was $71.3 \%$ for $2016-2017$ and a retention rate of $21.6 \%$. The 2015-2016 dropout rate was 5.0\% for Lucas High School. Both Aaron and Lucas High Schools are A1 schools which means they are under administrative control of a principal or head teacher and eligible to establish a school-based decision making council. These schools were chosen due to being two of the lowest performing schools in this district.

\section{Sample Design /Participants}

At each high school, Aaron High School and Lucas High School, two different groups of participants will be recruited for the study. The administrators at these urban high schools will identify the participants based on provided criteria. Students will be selected from grades ten, eleven, and twelve. The first category will consist of eight students who have been suspended for six or more days for level three (less severe) events. Level three interventions involve the short term (one to three days) removal of a student from the school environment because of the severity of the behavior. The short term suspensions may be appropriate when interventions and supports have been put in place but repeated offenses are still occurring. According to the Student Support and Intervention Handbook (2016) for the school district of this study, these events include leaving school grounds without permission, (unless in a school approved program that requires leaving school grounds) intentionally throwing an object that could potentially cause a disturbance or injury, failure to respond to questions or requests, and inciting a fight. The second category will consist of eight students who have been identified as having been suspended out of school for six or more days for level four (severe) events. Level four interventions involve the removal of the student 
from the school environment due to the severity of the behavior long-term (six to ten days). Long-term suspensions are used when student's behavior is jeopardizing the safety of others in the school. According to the Student Support and Intervention Handbook (2016) for the school district of this study, these events include physically fighting, direct profanity to an adult, robbery, sexual assault, and bringing a deadly weapon to school.

\section{Participant Confidentiality}

The school system where Aaron High School and Lucas High School are located has a protocol for research requests. The Data Management and Research Office provides an initial screening of research requests, looking for awareness and attention to several issues. These include (but are not necessarily limited to) the following:

- Alignment with the District Strategic Plan

- Appropriateness for public school settings

- Concern for confidentiality of individuals, students, families, schools, and work units

- Amount of intrusiveness of the research activities

- Time and effort required of staff and district resources

It will be the responsibility of the researcher to demonstrate why participation has more value than a burden to schools. Although the Data Management and Research will approve or not approve the research, teachers, principals, and school councils have final authority to agree or not to participate in any external research. All external research needs to have the permission from the Data Management Office before schools are approached by the researchers. I will ensure all participant's names remain confidential 
by using pseudonyms. All documents and data pertaining to the research study will be kept confidential. Letters will be sent to parents explaining all procedures. I will secure permission from the district in which the participants attend school prior to conducting the focus groups through semi-structured interviews. Parents of all potential student candidates will be sent letters explaining all aspects of the study (see appendix B). If permission is granted, students will also receive a letter explaining the study (see appendix C). Participation is strictly voluntary.

\section{Data Collection}

Participants in this research study will be audiotaped during the semi-structured interviews. Every effort will be made to make the participants comfortable and the location private. The researcher will code the data based on themes emerging from the semi-structured interviews. Semi-structured interview questions will be developed to create an open response type setting (See Appendix A). Recorded verbatim responses will be transcribed.

Qualitative semi-structured interview questions will be used in this study. There will be 16 student participants, eight per school, broken down into two categories. Each school will have four students who fall into the lesser offenses category and four students who fall into the greater offenses category. Student participants will share their experiences through responses to semi-structured interview questions. Semi-structured interviews consist of several key questions that help to define the areas to be explored, but also allows the interviewer or interviewee to diverge in order to pursue an idea or response in more detail (Chadwick, Gill, Stewart, and Treasure, 2008). This approach allows for flexibility in the discovery of information such as the emergence of a new theme that really was not on the radar prior to the interview. 
Anyan, (2013) defines the qualitative research interview as "an interview, whose purpose is to gather descriptions of the life-world of the interviewee with respect to interpretation of the meaning of the described phenomena". Face to face (FTF) interviews allow for the researcher to take advantage of social cues such as body language and tone of voice. This is in addition to the verbal answer the participant gives. Answers to other types of interviews such as telephone or virtual interviews are not spontaneous in nature like the FTF interviews. Another great aspect of FTF interviews is that the researcher has an opportunity to create a good interview ambience which may put the interviewee at ease. Audiotaping the interviews assures better accuracy than taking notes.

Most of the semi-structured questions are open-ended or nondirective. These questions deliberately give the participants as much latitude as possible for their responses. For this study, students who have experienced out of school suspension will be asked to participate in semi-structured interviews. They have an in-depth perspective because of their experiences with out of school suspension.

\section{Data Analysis}

The first principle of analysis of phenomenological data is to use an emergent strategy, to allow the method of analysis to follow the nature of the data itself which may emerge or change in the course of analysis (Waters, 2013). Data analysis is an interpretive act (Glesne, 2015). To get at the essential meaning of the experience, a common approach is to abstract out the themes. These are essential aspects "without which the experience would not have been the same", discovered through a thoughtful engagement with the description of the experience to understand its meaning (Glesne, 2016). Through the analysis of the data collected from the interviews, themes will emerge as to the perception of impact on academic motivation. Also, the meaning of the 
differences in the severity of the offenses for these participants will also be analyzed for emerging themes. The meanings are usually implicit, and need to be made explicit with thematic analysis. Themes will be identified as they emerge (Waters, 2013).

According to Krueger \& Casey (2002), the following guidelines for conducting interviews will be followed: Listen for vague or inconsistent comments and probe for understanding. Consider asking each participant a final preference question. Prepare for analysis immediately after the interview. Think about issues such as: What seemed to be the key themes of this discussion? What was surprising? How did this participant compare with prior participants? Do I need to change anything before the next participant? Note hunches, interpretations, and ideas. Label and file field notes, tapes, and other materials.

Inductive coding will be used as outlined by Creswell (2007) utilizing two phases of hand coding data. Phase one is referred to as "open coding." Open coding takes place during the first reading of data. During this first step, the data will be scanned for themes and common terms. During this phase, this researcher must make "sense" out of what was just uncovered and compile the data into sections or groups of information, also known as themes or codes (Corbin \& Strauss, 2008). The second phase of this process is referred to as "axial coding." During this phase, a second review of the data will take place. The data will be examined and assigned a label to themes found in phase one; these themes or codes will be developed by noting the consistency of certain phrases, expressions, or ideas that were common among research participants (Creswell, 2007). Deductive coding will also be used when working from the theoretical framework. One of the key tenets of social learning theory is that learning is not purely behavioral; it is a 
cognitive process that takes place in a social context. This can occur through observation or direct instruction. Learning can occur through the use of rewards or punishment. Schools are a social setting where students are expected to know the rules. Some students do not come equipped with the same social preparedness as others. The rules are not evident to them as they begin their school journeys'. Through deductive coding, the tenet of social learning theory that not all learning is behavioral but a cognitive process that takes in a social setting is used as an overarching theme identified through deductive coding to analyze the data.

\section{Analytic Memo}

Analytic memos will be used to write-up thoughts, summaries of findings, comments, observations or reflections during the interviews or immediately following. These notes are very important and a critical aspect of effectively analyzing data. These notes will be extremely helpful in writing up the study findings.

\section{Credibility}

Credibility in qualitative research is said to correspond to internal validity in quantitative approaches (Morrow, 2005). The credibility of my research will involve member checking to verify the accuracy of what was stated during the interview. The interviews will be tape recorded and transcribed.

\section{Validity}

Validity strategies in qualitative research are procedures that are used to show accuracy in the findings and persuade readers of this accuracy (Creswell, 2014). Some researchers argue that the term validity is not applicable to qualitative research but realize the need for some type of measurement to ensure accuracy (Golafshani, 2003). Researchers have developed more appropriate terms for validity in qualitative inquiry 
such as trustworthiness and quality. The words, descriptions, and thoughts developed through research are not inherently meaningful in themselves; it is the interpretation and analysis of data that give them meaning (Glesne, 2015). In the end, Trustworthinessis how plausible the researcher's ideas appear to be. Trustworthiness is about alertness to the quality and rigor of the study and ways to assess how well the research was carried out (Glesne, 2015). Several strategies have been identified as contributing to the trustworthiness of a study: It is important to develop a timetable to ensure adequate time is spent on each aspect of the study. Triangulation of the data by establishing themes from different perspectives of participants will add to the trustworthiness of the study. Finally, it is important to save and organize all documents related to the study leaving an audit trail.

\section{Ethical Considerations}

The semi-structured open-ended questions will be clear and relevant to the study. All participants will be informed of rights and responsibilities. My research may provide an avenue that will impact school disciplinary policy. The code of ethics instructs researchers to protect the privacy rights of participants. Through informed consent, participants will be informed of what to expect, know that participation is voluntary and that they can stop at any time. Benefits to participants must outweigh the risks. Respect for all participants' is crucial to the success of the research process.

\section{Transferability}

Transferability is applied by the readers of research. Although generalizability usually applies only to certain types of quantitative methods, transferability can apply in varying degrees to most types of research. Unlike generalizability, transferability does not involve broad claims, but invites readers of research to make connections between 
elements of a study and their own experience. For instance, teachers at the high school level might selectively apply to their own classrooms results from a study demonstrating that heuristic writing exercises help students at the college level (Barnes, Conrad, Demont-Heinrich, Graziano, Kowalski, Neufeld, Zamora, \& Palmquist, 2012).To assess the generalizability of this study, readers would have to report that the findings are consistent with their own experiences. Readers notice the specifics of the research situation and compare them to the specifics of an environment or situation with which they are familiar. If there are enough similarities between the two situations, readers may be able to infer that the results of the research would be the same or similar in their own situation (Barnes et al, 2012).

\section{Summary}

This study seeks to analyze the perceptions of students who have been suspended for six or more days and the impact that suspension has on academic motivation. Further, this study will investigate whether this perception changes with the severity of the offense. Lastly, this study examines if there is there a connection between the culture and climate of the school and out of school suspensions. It is my hope, as a researcher, that students are given a voice to express their perceptions. Additionally, it is my hope that these findings will help with the development of future disciplinary policies when taking into consideration the impact of out of school suspensions on academic motivation. 


\section{CHAPTER FOUR: SUMMARY OF RESEARCH FINDINGS}

As stated in chapter one, this qualitative study was designed to analyze the perceptions of students who have been suspended for six or more days and the impact of the suspensions on student academic motivation. Further, I investigated whether the student perceptions changed based on the severity of the offense. Third, an examination was done to determine whether there was a connection between the culture and climate of the school community (relevant to this study) and out of school suspension. Culture and climate would include whether there was a punitive school environment, types of relationships with staff and other students, and overall structure of the building.

Qualitative researchers embrace their involvement and role in their research. However, quantitative researchers also try to separate themselves from the research process as much as possible. This is one strong reason I chose qualitative research. I wanted to engage with my participants and give them a voice to express their feelings about my topic. Another reason for using the qualitative approach was that the researcher is the instrument in the research versus using an instrument for quantitative research. Truly engaging in research probing for deeper understanding rather than examining surface features is another aspect of qualitative research that is significant to my choice (Golafshani, 2003). 
Phenomenological inquiry design was utilized for this study. This design typically involves using interviews (Creswell, 2014). The researcher seeks to understand the experiences and perceptions of each participant, and to examine similarities and differences across cases (Glesne, 2015). When turning to analyzing data in a phenomenological study, the first principle is to use an emergent strategy; and allow the method of analysis to follow the nature of the data itself which may emerge or change during analysis (Waters, 2013). To get at the essential meaning of the experience, a common approach is to identify key themes. The researcher seeks to understand the experiences and perceptions of each participant, and to examine differences and similarities among them (Glesne, 2015).

\section{Theoretical Framework}

Social learning theory was used as the theoretical framework for this study. Social Learning theory, as it applies to my study, discusses how the social curriculum is less explicit than the academic curriculum, but the rules, expectations and consequences are no less important than the academic curriculum (Skiba \& Peterson, 2003). According to Skiba and Peterson, (2003), the meaning of discipline is far different than what is commonly thought. The word discipline comes from the Latin word disciple, which means to teach or comprehend. Components of the social curriculum are explained in figure 3. 
Figure 3:

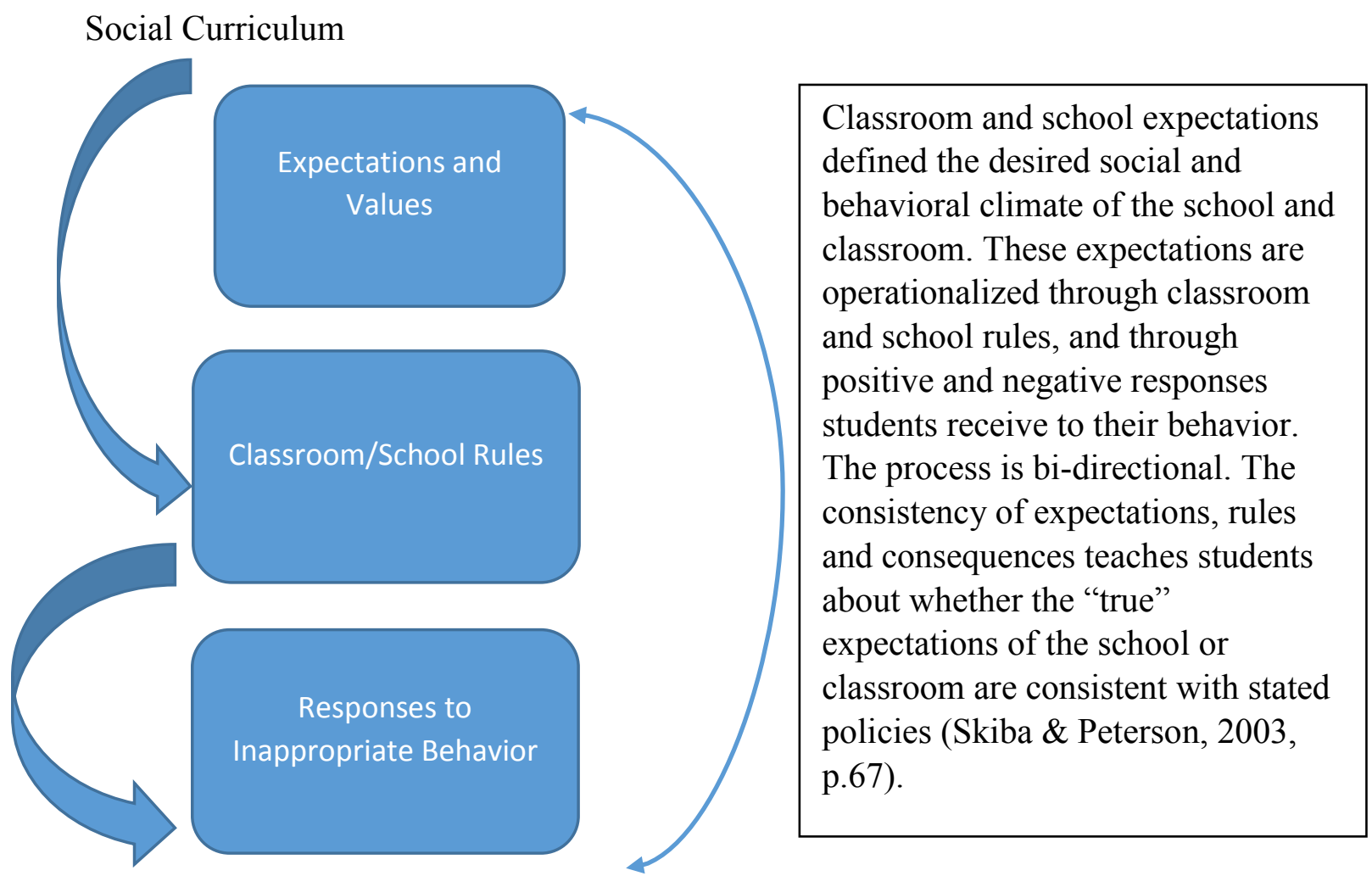

One of the key tenets of social learning theory is that learning is not purely behavioral; learning is a cognitive process that takes place in a social context. This can occur through observation or direct instruction. Most students come to school with the ability to recognize acceptable classroom behaviors. There are some students who do not recognize those behaviors because they were not taught this in the home setting. Many home environments model a different way to handle issues from what the child has observed at home (Skiba \&Peterson, 2003). When a student responds in a manner they have seen at home but is not socially acceptable according to the school, disciplinary action is taken. 


\section{Interview Protocol}

In this study were 16 high school students currently in 11th and 12th grades ranging in age from 15-19 years. There were eight African American males, seven African American females, and one white female. A more diverse population of student participants was sought. After multiple unsuccessful attempts to interview a more diverse participant sample, the current sample was established. Ethnicity, age, race, gender and socioeconomic status were not factors in this particular study. The student participants had to have been suspended out of school for a total of six or more days for the 2017-18 school year to qualify to participate. The student participants attended two high schools. Eight were from Aaron High School and eight were from Lucas High School in a large urban school district in the southeastern United States. At each high school the students were divided into two categories. One category consisted of four students who have been suspended for six or more days for level three (less severe) events. Level three interventions involve the short term (one to three days) removal of a student from the school environment because of the severity of the behavior. The students who were in the greater offense category and had at least one six-day suspension for the 2017-2018 school year also had a history of previous suspension for the year and previous years. According to the Student Support and Intervention Handbook (2016) for the school district of this study, these events included leaving school grounds without permission, intentionally throwing an object that could potentially cause a disturbance or injury, failure to respond to questions or requests, and inciting a fight.

The second category consisted of four students who had been identified as having been suspended out of school for six or more days for level four (severe) 
events. Level four interventions involve the removal of the student from the school environment due to the severity of the behavior long-term (six to ten days). Long-term suspensions are used when a student's behavior is jeopardizing the safety of others in the school. According to the Student Support and Intervention Handbook (2016) for the school district of this study, these events included physically fighting, direct profanity to an adult, robbery, sexual assault, or bringing a deadly weapon to school.

The sample size for this research study was 16 subjects, eight per school. Individual interviews were conducted with all student participants to identify perceptions about out of school suspension and the impact of those suspensions on academic motivation. Participants in this research study were audiotaped during the interviews. Each student was asked fifteen semi-structured interview questions. The questions were specifically designed to draw information based on the research questions for this study. The questions were developed in order to create an open response type setting (See Appendix A) verbatim. All students were asked the same questions using the same wording . Semi-structured questions helped to define the areas to be explored, but also allowed the participant to pursue an idea or response in more detail. The questions were designed to solicit information surrounding the following research questions: Research Question 1: How do students perceive out of school suspensions' impact on their academic motivation? Research Question 2: Do their perceptions change based on the severity of the offense? Research Question 3: Is there a connection to the culture of the school community and out of school suspension? Recorded responses were transcribed verbatim. The transcripts were analyzed and coded. 
I composed parent and student letters to the parents/guardians of those students 17 or younger identified by school administrators at each school who met the criteria to participate. Parents or guardians were asked to sign and return the consent forms to the school. Potential student candidates 18 years old or older were also identified by school administrators at each school. They were handed letters explaining the study and then, if interested, consent forms to sign. I was not allowed to know who the participants were until the signed consent forms were returned due to regulations in the school district in which the study took place. Pseudonyms were used to ensure confidentiality. The students chose their own pseudonyms so there were four students, two each of the same name. Those two names were identified by adding the numberone or two after the name and attached to the pseudonym for clarity. To safeguard identity, audio-recorded interview group information with real names and corresponding pseudonyms were kept in a locked storage area accessible only to me. Any digital documents were stored on a password protected computer accessible only to me.

Table 1.

Demographic Information

\begin{tabular}{|l|l|l|l|l|l|l|}
\hline \multicolumn{1}{|c|}{ Name } & \multicolumn{1}{|c|}{ Race } & \multicolumn{1}{|c|}{ Gender } & \multicolumn{1}{|c|}{ Age } & School & $\begin{array}{l}\text { Lesser } \\
\text { Offenses }\end{array}$ & $\begin{array}{l}\text { Greater } \\
\text { Offenses }\end{array}$ \\
\hline Ashley One & Black & Female & 18 & Aaron & & X \\
\hline Ashley Two & Black & Female & 18 & Lucas & & $\mathrm{X}$ \\
\hline Ava & Black & Female & 17 & Aaron & X & \\
\hline Bobby & Black & Male & 18 & Aaron & & $\mathrm{X}$ \\
\hline Brittney & Black & Female & 17 & Aaron & $\mathrm{X}$ & \\
\hline David & Black & Male & 18 & Lucas & $\mathrm{X}$ & \\
\hline
\end{tabular}




\begin{tabular}{|l|l|l|l|l|l|l|}
\hline Hank & Black & Male & 17 & Aaron & X & \\
\hline Jaylin & Black & Male & 18 & Aaron & X & \\
\hline Littles & White & Female & 18 & Lucas & X & \\
\hline London & Black & Female & 17 & Lucas & X & \\
\hline Louis & Black & Male & 18 & Lucas & & $\mathrm{X}$ \\
\hline Montez & Black & Male & 18 & Lucas & & $\mathrm{X}$ \\
\hline Mr. X & Black & Male & 18 & Lucas & $\mathrm{X}$ & \\
\hline Rich Porter & Black & Male & 18 & Aaron & & $\mathrm{X}$ \\
\hline Samantha One & Black & Female & 18 & Aaron & & $\mathrm{X}$ \\
\hline Samantha Two & Black & Female & 18 & Lucas & & $\mathrm{X}$ \\
\hline
\end{tabular}

\section{Data Analysis}

All interviews were transcribed by Rev.com, a transcription company. Once transcription was complete, I carefully read all interview transcripts and began the inductive coding process. According to Glesne (2015), the coding, categorizing, and theme-searching process is a time when you think with your data, reflecting upon what you have learned, making new connections, gaining new insights, and imagining how the final write up will appear. Inductive coding was used as outlined by Creswell (2007) employing two phases of hand coding data. Phase one is referred to as "open coding." Open coding takes place during the first reading of data. During this first step, the data was scanned for themes and common terms. During this phase, I made "sense" out of what was just uncovered and compiled the data into sections or groups of information, also known as themes or codes (Corbin \& Strauss, 2008). 
The second phase of this process is referred to as "axial coding." During this phase, a second review of the data took place. The goal of axial coding is to determine which codes from the open coding are the dominant ones and which ones are the less important ones. According to Salda.a (2016) this method aims to link categories with subcategories and asks how they are related. Themes begin to emerge based on the linking process. Depending on similarities in the categories, connections are made to combine into themes. There were 19 emerging themes in my study which were narrowed down to seven based on the similarities of the themes. These were: 1) Relationships with school staff, 2) Communication between students, parents and staff;

3) Student voice; 4) Impact of out of school suspensions on academic progress;

5) Strategies/Alternatives for behavior intervention; 6) Support Services, and 7) Fair treatment. These themes were also used to determine whether academic motivation changed based on severity of the out of school suspension offense and whether there was a connection between out of school suspensions and the culture of the school.

Table 2

\begin{tabular}{|l|l|}
\hline \multicolumn{1}{|c|}{ 19 Subthemes } & \multicolumn{1}{c|}{ Seven Themes } \\
\hline $\begin{array}{l}\text { Relationships with school personnel are } \\
\text { extremely important and can help a student } \\
\text { be successful }\end{array}$ & $\begin{array}{l}\text { Relationships with school } \\
\text { staff }\end{array}$ \\
\hline
\end{tabular}




\begin{tabular}{|c|c|}
\hline $\begin{array}{l}\text { - Students suggested "actually listening" and } \\
\text { "communicating" with students when there is } \\
\text { a behavior issue would improve behavior } \\
\text { overall } \\
\text { - Upon returning to school after suspension, } \\
\text { most students had to explain why they were } \\
\text { out to other students but were not treated } \\
\text { badly } \\
\text { - Students expressed being labeled by other } \\
\text { students and staff members if they were } \\
\text { suspended multiple times as a "bad kid" or } \\
\text { "trouble" } \\
\text { - Some guardians were home with their } \\
\text { student, others had to work }\end{array}$ & $\begin{array}{l}\text { Communication between } \\
\text { students staff, and parents }\end{array}$ \\
\hline $\begin{array}{l}\text { - Students felt that they were not given the } \\
\text { opportunity to explain themselves and this } \\
\text { may have changed the discipline outcome } \\
\text { - Students were extremely appreciative of the } \\
\text { opportunity to be given a voice }\end{array}$ & Student voice \\
\hline $\begin{array}{l}\text { - Out of school suspensions are not effective } \\
\text { at deterring unacceptable behavior } \\
\text { - Students overwhelmingly stated that being } \\
\text { suspended out of school was a big contributor } \\
\text { to them being behind in their academics } \\
\text { - Students struggled to get make-up work even } \\
\text { after asking for it } \\
\text { - Students were anxious to get back to school } \\
\text { to "catch up" on what assignments they } \\
\text { missed } \\
\text { - Students felt angry about being suspended } \\
\text { - Students felt ashamed about being suspended }\end{array}$ & $\begin{array}{l}\text { Impact of out of school } \\
\text { suspensions on academic } \\
\text { motivation }\end{array}$ \\
\hline $\begin{array}{l}\text { Most students were at home during } \\
\text { suspension but felt that the opportunity to get } \\
\text { into more trouble was definite possibility } \\
\text { - Students felt in-school suspension was a } \\
\text { better option than out of school suspension } \\
\text { for safety reason (not out where more trouble } \\
\text { can occur) and making up work is easier } \\
\text { - Students agreed that teaching conflict } \\
\text { resolution, coping skills, and anger } \\
\text { management would help prevent behaviors } \\
\text { leading to suspension }\end{array}$ & $\begin{array}{l}\text { Strategies/Alternatives for } \\
\text { behavior intervention }\end{array}$ \\
\hline $\begin{array}{l}\text { - Students felt there is a need for more } \\
\text { counselors/social workers/support staff in the } \\
\text { school buildings }\end{array}$ & Support Services \\
\hline
\end{tabular}




\begin{tabular}{|c|c|}
\hline 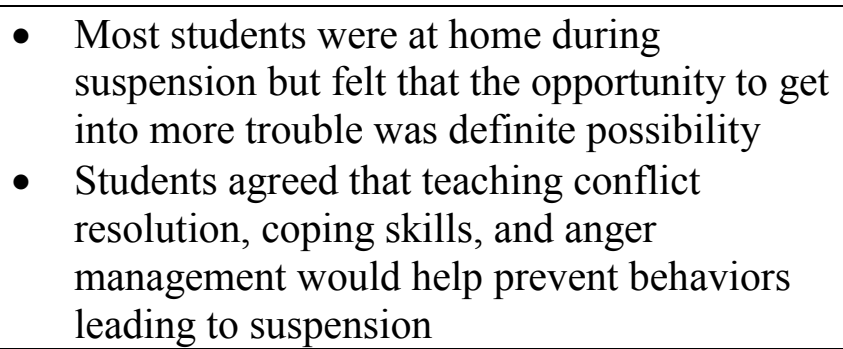 & \\
\hline $\begin{array}{l}\text { - Students feel that many times the reasons } \\
\text { they were given for being suspended out of } \\
\text { school were unclear and/unfair } \\
\text { - Students shared that parents/guardians were } \\
\text { upset about their out of school suspension but } \\
\text { felt it was unclear as to why they were } \\
\text { suspended } \\
\text { - Students felt that they were not given the } \\
\text { opportunity to explain themselves and this } \\
\text { may have changed the discipline outcome }\end{array}$ & Fair treatment \\
\hline
\end{tabular}

\section{Researcher Positionality}

The term positionality both describes a person's worldview and the position they have chosen to adopt in relation to a specific research task (Foote and Bartell, 2011). Richard Milner (2007) created a framework to guide researchers into a process of racial and cultural awareness, consciousness, and positionality as they conduct education research. According to Milner (2007), if researchers are not aware of the huge role of their own and others' racialized positionality and cultural ways of knowing, the results can be harmful to individuals and communities of color. In my research with a diverse population, Milner's framework helped me be more aware of my own cultural issues. The researcher should be engaged and forthright in handling these issues. This is why it is so important for the researcher to really try to understand their own racial and cultural heritage prior to conducting research. Utilizing a framework such as Milner's to research one's own beliefs is very important to the research process because sometimes it is hard to know just where to begin when faced with this type of reflection. Milner's framework 
rejects practices in which researchers disassociate themselves from the research process. According to Milner (2015) it may be necessary for researchers to consider dangers seen, unseen, and unforeseen in conducting research. By seen dangers, Milner is referring to the dangers that can explicitly emerge as a result of the decisions researchers make in their studies. Unseen dangers are those that are hidden, covert, implicit, or invisible in the research process. Unforeseen dangers are those that are unanticipated or unpredicted in a research project based on the decisions that researchers make in the research process. Milner states:

The premise of the argument is that dangers seen, unseen, and unforeseen can emerge for researchers when they do not pay careful attention to their own and others' racialized and cultural systems of coming to know, knowing, and experiencing the world. For these reasons guides and frameworks are needed to (a) contribute to and extend the discourse about researchers' roles, responsibilities, and positionality; (b) assist and empower researchers in the process, production, and outcomes of inquiry; and (c) hold researchers more accountable to the communities and people with whom they conduct research. Consequently, the proposed framework attempts to guide researchers from various racial and cultural backgrounds - White researchers and researchers of color-to deeper levels of awareness and consciousness in conducting education research (p. 389).

Addressing self in relation to others is part of Milner's framework. This is where the following question is asked, "What is the racial and cultural heritage of the participants in the study?" In order to address self in relation to others, it was necessary to develop a 
sense of my own frame of reference, which is why researching self is so important. I have workedwith students for 25 years in schools with very diverse populations. I believe that working with students is a matter of meeting a student where they are and extending a hand. Some take it readily and others hesitate. It is about forming a trusting relationship. Sometimes, even this is not enough.

Moser (2008), a White Canadian middle class graduate student conducting fieldwork in Indonesia, found that it was aspects of her personality, such as her social skills, her responses to people, and how she conducted herself that were the main criteria by which she was judged. She observed that as villagers got to know other scholars who shared similar "positionalities" (well-educated, White, wealthy by villager standards, non-Muslims) they were less concerned about positionality and more about personality and the unique individual social and emotional qualities of the researchers. She gathered this from the way the local villagers talked about them and treated them. This article hit home with me because it discusses the importance of personality as well as positionality. I truly believe that they work hand in hand. The reality is that not all researchers will produce the same findings because "we all speak from a particular place, out of a particular history, a particular experience, a particular culture, without being contained by that position" (Hall, 2000).

The rest of this chapter addresses the seven strong themes that came from the 19 subthemes. The subthemes were extracted from the answers to the 15 semi-structured interview questions surrounding my research questions. The differences in answers based on the severity of the offense are also noted as each of the seven themes is addressed. Some of the subthemes fit into more than one major theme due to linked connections. 


\section{Impact of Out of School Suspension on Academic Motivation}

The impact of out of school suspensions on academic motivation was a major theme that emerged from the answers to the semi-structured interview questions. All of the students responded that they felt bad when they were suspended. They used these words to describe how they felt: miserable, mad at themselves, disappointed in themselves, made a mistake, felt terrible, felt like a failure, distraught. London, in the lesser offense category explained further the way it made her feel:

When I get suspended, it's normally over petty stuff, so whenever I'm suspended I feel like, well dang, "is that what you all wanted to keep doing?" Keep suspending me, taking me from my education, but then when I get suspended, I be thinking, I could have done something else, or avoided that situation and getting suspended.

Hank, who fell in the lesser offense category, stated that "because when you get suspended you're basically falling behind in school, and it's hard to catch back up." Montez, who fell in the greater offense category, stated, "It's not a good thing (suspension), like just be home bored and all that. You just missing out on work that you could be doing trying to graduate and all that." Once students fall behind it is especially hard to catch up to their peers. This could cause them to feel overwhelmed and one student even felt there was no point in trying after falling so far behind and it made the student then want to give up.

There was a significant difference between the students in the greater offenses category and the students in the lesser offenses category in the answer for the question, "when you were suspended, was it hard to catch up?" Six students out of eight in the 
lesser category felt it was harder to catch up when suspended out of school. Only three students out of the eight in the greater category felt it was hard to catch back up. Most students who had at least one six-day suspension (greater offense category) had a history from previous years of multiple suspensions. They knew the process of how to get the make-up work by either asking for it before leaving the building or when they got back. Those students who had a less than six day suspension (lesser offense category) were not exactly sure what to do to make up their work because this was not something they were used to dealing with.

Students were all at home during their out of school suspension with the exception of one who was at church doing community service. Rich Porter, in the greater offense category, stated: "I was at home. I would try to do as much make up work as I can, but if I wasn't at home, I was at work. So, like I would go into work early”. Some of the students in the greater offenses category were at home with a sibling who was also suspended from school. When asked how they felt about coming back to school, Ashley One, in the greater offenses category, stated: "I was behind. I needed to get all my work up so I could graduate this year." Hank, in the lesser offense category, also added: "To try and catch back up on my work and grades." Many of the students responded that they needed to get back to school to catch back up.

When students were asked if being suspended out of school affected their grades, all students stated that their grades were negatively impacted by being suspended out of school. David, in the lesser offenses category, stated, "It affected my grade because some work I couldn't get, like the test or stuff, I gotta be at school to do because they don't want us to go home and cheat on it or nothing like that." When asked if out of school 
suspensions help students with their behavior, all students in the lesser offenses category responded that out of school suspensions are not effective, and six out of eight students of the greater offenses category felt they were ineffective. Montez, in the greater offenses category, stated "being out of school is just another reason for a kid to be missing his work. Can't do the work, you can't graduate." Hank, in the lesser offenses category, shared: "Because if they get in a fight and they lose the fight, they're just gonna come back to school and fight the same person again and get suspended again”. Brittney, in the lesser offenses category, offered this feedback: "No because putting somebody out of school isn't going to fix the way they act." Clearly, students voiced that out of school suspensions are not effective at changing behavior and adversely affect academic success.

\section{Relationships with School Staff}

One of the interview questions asked about the importance of relationships with school staff. All students responded with great emphasis that staff/student relationships were extremely important in the school. London, in the lesser offenses category, offered this statement about relationships. She stated:

It is important because they can change your mind-set on things, like I came in here this morning feeling like I was going to give up, and not wanting to do stuff, but just like over everything. But, I had this one special person, she helped me call this job that I been trying to start working at for the longest. Now I get a call Friday, yes, I get to start maybe.

The importance of relationships was a strong theme that emerged as students spoke about the different staff members who made an impact on them. Many talked about how if it had not been for certain staff members they would not be able to come to school and try to be successful. 
Samantha, in the greater offenses category, stated the following about relationships:

Because you always need like a trusted adult around, because when I was into all of that, I always had that one adult I could go to. She'd try to keep me out of trouble, try to help me out and all of that. When I got suspended I emailed her. I was like, can you gather my work for me? She did it for me, when I got back my work was just sitting right there ready for me from all classes. I think it's just important that you got somebody like that.

When students talked about relationships with adults in the school setting, they included all staff members, not just teachers and administrators. It was not about the position the person held; it was how much the staff member showed they cared by asking them questions and listening to what they had to say. Many of the study participants expressed a desire to be heard when there was an issue. A chance to explain themselves was often the comment used.

\section{Communication between Students, Parents and Staff}

When asked who was at home with the student, most of those students with lesser offenses stated they were at home with a parent/guardian. There were only a couple of students with greater offenses who had a parent/guardian at home during their suspension. Most of the parents who were not at home with their student were at work. When asked about their parent's response about being suspended London, in the lesser offenses category, shared, "She's pretty mad. She's saying that I gonna fail if I keep getting suspended because, you know, missing work." Ashley, in the greater offenses category, said her mom stated: "Suspended for breaking up a fight?" And she was like, "Are you for real?" She was like I get suspended for everything now." Some students felt 
that when you are suspended more than once, you get labeled as a "bad" kid and treated differently than the "good" kids. Bobby, in the greater offense category, stated the following about how schools' can do a better job dealing with behavior: "Instead of suspending them right off the top, talk to them. Ask what happened. At least hear both sides of the story." These responses show that there is a need for better communication between parents, students and school staff. Parents and students often question the reason for an out of school suspension and need a better explanation by school staff.

When students were asked what schools can do to help students make better choices, there was much discussion. In both categories, most students felt communication was the key to helping students. The students emphasized that they need someone to really listen to them. Also, in both categories, students felt that more support staff is needed to help students with counseling issues, anger management, and coping skills. Bobby, in the greater offenses category, stated:

I think the communication before you get in trouble that might help. To see actually why they did what they did. And because some people they'll listen to what you did. I think this communication to try to figure out exactly what the problem was, it would be good. It'll save some suspensions.

Ashley, in the greater offenses category, stated, "I feel like we are not heard". And, London, in the lesser offenses category, offered this suggestion; "Sit down and have a civilized conversation with them, instead of yelling at them." Jaylin, in the lesser offenses category, stated the following:

You have to, like...students should be able to, like, if you know you have anger 
Problems, you should be able to sign up for something with your counselor and it'd be like....okay, we did it in elementary school. We had like the little anger management class and your parents signed you up for it and then you go......I think it was every Wednesday, sixth period, and you talk about it and that just helps. Well, it helped me a lot, just being able to talk about your frustrating problems.

When asked if they had gotten into trouble while out of school for suspension, one student in each category said they had gotten into trouble while suspended. All of the students felt that out of school suspensions open the door for students to get into more trouble, possibly involving law enforcement. Mr. X, in the lesser offenses category, expressed:

That (suspension) opens up chances for them to get deeper into the streets, being pushed out of school. You hear me? Because they got suspended, or it opens up the chances for them to like lose...opens up the door for them to go in a different direction. Throw away their whole life just based off starting here. You feel me? Starting off with suspension can lead to more things.

\section{Student Voice}

Students expressed a need for better communication and a chance to explain themselves when facing disciplinary consequences. Each student who was interviewed was thankful to be able to talk to me and to be able to have a voice in this process. London, in the lesser category, stated: "Adults need to learn how to listen to kids, sitting down and having a civilized conversation with them, instead of yelling at them". Or, what Bobby, in the greater category, says about communication with staff: "Don't get me wrong, some people need to get suspended. It's like, at least talk to them. Don't go ahead 
and suspend them, at least hear both sides of the story. They (staff) don't even do that".

During the interview process, students shared that there may have been times when the discipline would have been different if the administrator had given them a chance to explain further the circumstances surrounding the incident. Or, the discipline would have been the same, but, at least, they would feel like they had been heard and the staff cared about what they had to say.

\section{Fair Treatment}

Brittney, in the lesser category, stated: "half the time I get suspended for stupid stuff. She felt that suspension was unfair and unclear. Littles, also in the lesser category, had this say:

Being suspended from school, it's a good thing and it's a bad thing. Because when you get suspended, because you're suspended for a reason is good but not for little bitty things. So, if you get suspended, it relieves you from what the problem was you had in school, but, it's also a bad thing because it then puts you back further on your work.

There seemed to be much confusion about the fairness of certain suspensions on the part of the students and the parent. Many students and parents did not understand the reasoning behind the suspension. Additionally, many students felt that there were big discrepancies in the reasons for suspension. They questioned the difference between being suspended for a fight versus being suspended for wearing a hoodie. "Why not just make them take off the hoodie instead of suspending them?" was the general consensus offered by the students. Most students viewed fighting as an acceptable reason for being suspended but wearing a hoodie was seen as something that could be fixed immediately so why suspend someone for that? 


\section{Support Services}

When asked about suggestions for alternatives to out of school suspension, students suggested the following support services: More counselors, training for peer mediation/conflict resolution, anger management sessions, and more home school coordinators. Bobby, in the greater category stated: "Peer mediation stopped me from so many fights in middle school, I ain't gonna lie. You have to talk."

According to a study done with three middle schools on the effectiveness of conflict resolution/peer mediation, the implementation of these programs can alter students responses to conflict in positive ways. There was an overall decline in these three middle schools in referrals for disruptive and aggressive behavior (Daunic, Landry, Miller, Robinson \& Smith, 2000). I have personal experience training students in conflict resolution and implementing a peer mediation program for 12 years with a $98 \%$ resolution rate. To see these students become empowered by their ability to help others resolve conflicts is amazing. Being able to teach students conflict resolution and how to mediate other students is a win-win situation. Peer mediators are seen as leaders in the school and often resolve conflicts when they occur between students. This decreases the chances for conflicts to escalate which lead to less out of school suspensions and creates a less punitive environment in the school.

\section{Strategies/Alternatives for Behavior Intervention}

All of the students' in the lesser offenses category felt in-school alternative placement (ISAP) was a better alternative than out of school suspension In the greater offenses category, almost all of the students felt in-school alternative placement (ISAP) was the best alternative. Rich Porter, in the greater offenses category, had the following to say about out of school suspensions and whether they are help with behavior: 
Not really because the only thing it's doing is just letting them be outside on the streets and not in school. When they're in school, their parents know where they are. They're safe, they're getting their education, getting their work done. But I feel like, in most situations, I think a lot of situations can be avoided if suspensions were like in-school suspension.

Ava, in the lesser category, felt that instead of out of school suspension, why not have students clean up the cafeteria or something like that. This would allow for students to feel like they have accomplished something to help the school rather than get behind in their classes.

\section{Conclusion}

My research questions were designed to solicit information surrounding the following research questions:

Research Question 1: How do students perceive out of school suspensions' impact on their academic motivation? Research Question 2: Do their perceptions change based on the severity of the offense? Research Question 3: Is there a connection to the culture of the school community and out of school suspension? Based on answers to semi-structured interview questions during individual student interviews the data helped deepen the understanding of the impact of out of school suspension on academic motivation. The answers also provided feedback regarding whether the motivation changed based on the severity of the offense Moreover, this study determined a connection between the culture and climate of the school and out of school suspension.

All of the students responded that they felt bad when they were suspended. They used these words to describe how they felt: miserable, mad at themselves, disappointed in 
themselves, made a mistake, felt terrible, felt like a failure, distraught. Many felt that they were so behind that they felt like they could not catch up. All students stated that their grades were negatively impacted by being suspended out of school. Most students expressed that out of school suspensions were not an effective way to change behavior. They suggested alternatives that did not include exclusionary discipline.

There were some significant differences between the lesser category of suspension and the greater category of suspension. Making up work seemed to be easier for the greater offense category because these students were used to the suspension process and knew how to obtain the work. In the lesser offenses category, more students were at home with a parent/guardian than those in the greater offenses category when suspended. More students in the lesser offenses category stated that their parent/guardian was upset with them. The last difference is that all of the students in the lesser offenses category asked for make-up work, however, only a little over half of students in the greater offenses category asked for make-up work.

There is a definite connection between the culture and climate of the school community and the impact on academic motivation on out of school suspensions. The importance of relationships with school staff was a major theme that emerged in student interviews, as well as communication between staff, parents and students. These factors all impact the culture and climate of the school environment. Students were appreciative of the time they had to express their opinions and give suggestions about alternatives to suspension. Research limitations and implications for future research will be discussed in chapter five. 


\section{CHAPTER FIVE: SUMMARY, CONCLUSIONS, AND RECOMMENDATIONS}

\section{Introduction}

Chapter five contains a summary of the study, discussion of the results in relation to the literature, implications for school leaders, reflections of the researcher, as well as recommendations for future research. The purpose of this qualitative study was to research the perception of the impact of out of school suspensions on students' academic motivation from a student perspective. Further, this study investigated as to whether this perception of impact on acidic motivation changed based on the severity of the offense.

Third, an examination was conducted to determine out if there was a connection between the culture (environment, treatment of students) of the school community and out of school suspension. The findings of this study were derived from student participants' voices who had experienced out of school suspension. Semi-structured interviews were conducted with each participant in order for students to express their perceptions regarding the impact of out of school suspensions on their academic motivation. There were seven major themes that emerged when analyzing the data: 1.) Impact of out of school suspensions on academic motivation; 2.) Communication between students, parents and staff; 3.) Importance of relationships with school staff; 4.)Student voice; 5) Strategies/alternatives for behavior intervention; 6) Fair treatment, and 7) Support services. 


\section{Summary}

In chapter one, issues relating to the impact of out of school suspension were introduced. The following issues describe what the research indicates are the most prominent impacts of out of school suspension; nearly 3.5 million public school students were suspended at least once in 2011-2012 adding up to 18 million instructional days lost in one school year (Skiba \& Losen, 2015); exclusionary discipline may lead to poor academic outcomes for the student, increased likelihood of dropping out of school, and an introduction to the criminal justice system (Cueller \& Markowitz, 2015); students who have been suspended are three times more likely to drop out of school than their peers (Ekstrom et al., 1986; Raffaele Mendez, 2003; Wehlage and Rutter, 1986); being suspended from school also increases the chances a student will feel disconnected, intensify conflict with adults, and impact a youth's choice to engage in criminal activities (Skiba et al., 2006); Researchers have concluded that suspension is also a predictor of future suspensions, not a deterrent (Rafaele \& Mendez, 2003); use of suspension is associated with lower academic achievement, an increased risk of deviant behavior and impacts on time graduation (Skiba \& Losen, 2015).

In chapter two, literature was reviewed to further investigate the impact of out of school suspensions on academic motivation. The history of school discipline was presented first. Factors associated with suspensions such as race and gender, suspensions by school type (elementary, middle and high) and the connection between out of school suspension and the impact on educational outcomes were researched next. Alternatives to out of school suspension were also discussed in chapter two. Additionally, there was literature reviewed to determine whether the culture and climate of the school was connected to out of school suspensions. This included the relationships with staff 
members, opportunities for students to voice their concerns, and overall climate of the building.

Chapter three explained what qualitative research is and why this design was used to conduct this study. The methodology used was a phenomenological inquiry design and the social learning theoretical framework was used to conduct the study. The high schools that were used for the study were described as well as the sample population. This chapter also addressed confidentiality issues concerning the research. The chapter concluded with the description of data collection and analysis procedures, credibility, reliability, and ethical considerations.

Chapter four was a summary of all research findings based on 19 themes that emerged and the seven subthemes that connected many of the themes together. Student quotes and researcher observation backed up the themes as each one is explained. The themes that emerged were based on the answers to the 15 semi-structured interview questions. The interview questions were developed to get answers to the three research questions. Now, chapter five will center on the three research questions and the conclusions that can be made from the research. Many of the themes could go under multiple research questions due to the impact on both academic motivation and school climate and culture from out of school suspensions.

\section{Discussion of the Results in Relation to the Literature Research Question One Discussion}

Research question one: How do students perceive out of school suspensions' impact on their academic motivation?

Three of the seven themes that emerged from the semi-structured interview questions related mainly to research question one: 1) Impact of out of school suspensions 
on academic motivation 2) Strategies/alternatives for behavior intervention 3) Support services. The literature shows that when students experience out of school suspension and then return to school, many feel they cannot catch back up to their peers. This may be the final straw as a student struggles to decide whether they should drop out of school (Blomberg, 2003). In my study, when asked about how it felt to be suspended, student participants felt that it was very hard to catch up after being suspended. Students overwhelmingly stated that being suspended out of school was a big contributor to them being behind in their academics. Students also struggled to get make-up work, even after asking for it.

Research shows that students who have a history of suspension, more than any other characteristic, causes the greatest negative consequence on student educational outcomes (Cobb-Clark, Kassenboehmer, Le, McVicar, \& Zhang, 2015). Sharkey and Fenning (2012) cited research showing that suspension is not only ineffective at deterring behavior infractions it is also connected to academic failure and school dropout. In my study, some student participants felt that once you get behind, it is easy to give up. Instead of students learning from their mistakes, students stated that most are just going to continue to get suspended with some even trying to get suspended out of school. One student said it was like a vacation.

There may be several factors that impact the relationship between suspension and academic motivation. All students in my study felt that their grades were negatively impacted by being suspended out of school. Some felt that, at a certain point, they lacked the motivation to even try. Students with a history of suspension have reduced graduation rates (Cobb-Clarket al, 2015). Student participants in my study all felt bad when they 
were suspended. Most were mad at themselves, felt like a failure, or stated they made a mistake.

A key contributor to school disengagement by high school students is that when problem behaviors occur, school administrators choose to use punitive measures such as suspension or expulsion (Flannery et al., 2014). Instead of using the exclusionary measures, high schools need discipline practices that improve long term student outcomes (Flannery et al., 2014).

\section{Research Question Two Discussion}

Research question two: Do their perceptions change based on the severity of the offense?

In a study conducted of suspensions and achievement that spanned three years, Arcia (2006) found that, prior to suspension, students who received the highest number of out of school suspension days had lower achievement levels than students who receive fewer or no suspension days. In my study, when divided into the greater offense and less offense categories, there were significant differences in answers to the semi-structured interview questions. Twice the number of students in the lesser offenses category felt it was hard to catch up when suspended from school. Another difference that was important was that $62.5 \%$ of students in the lesser offenses category were at home with a parent/guardian when suspended. Only $25 \%$ in the greater offenses category were at home with a parent/guardian while suspended. In addition, $62.5 \%$ of the students in the lesser offenses category stated that their parent/guardian was upset with them. In the greater offenses category, only $37.5 \%$ were upset with their students. Students in my study shared that parents/guardians were upset about their out of school suspension but felt it was unclear as to why the student was suspended. 
All students in the lesser offenses category asked for make-up work but only $62.5 \%$ of students in the greater offenses category asked for make-up work. When asked if out of school suspensions helped changed behavior, all students in the lesser offense category said it did not help students change their behavior, and $75 \%$ in the greater offenses category felt it did not change behavior. Results show that, based on the student interviews, out of school suspensions are not effective at deterring unacceptable behavior. In school suspension (ISAP) was repeatedly suggested as an alternative for out of school suspension, $100 \%$ of students in the lesser offenses category and $62.5 \%$ in the greater offenses category suggested ISAP as an alternative. All students in my study felt that out of school suspension was an ineffective way to change behaviors. Students felt in school suspension was a better option than out of school suspension for safety reasons (not out where more trouble can occur) and making up work is easier. Students felt that they were not given the opportunity to explain themselves and this may have changed the discipline outcome. Students suggested "actually listening" and "communicating" with students when there is a behavior issue would improve behavior overall. Students feel that many times the reasons they were given for being suspended out of school were unclear.

Students agreed that teaching students about peer mediation, conflict resolution, and coping skills would help prevent behavior leading to out of school suspension. Students felt there is a need for more counselors/social workers/support staff in the school buildings. 


\section{Research Question Three Discussion}

Research question three: Is there was a connection between the culture (environment, treatment of students) of the school community and out of school suspension?

Themes that emerged from the answers to the semi-structured interview questions relating to question three were: 1) Importance of relationships with school staff 2) Communication between students, parents, and staff 3) Student voice and 4) Fair Treatment

Survey data from a study of all of Chicago's schools found that the relationships developed between parents, teachers, and students was a much better predictor of feelings of safety (Losen \& Skiba, 2015). A trend in research on out of school suspension shows a dramatic emphasis on relationships being a key factor in what leads to students being suspended or not. The better the relationship is between students and teachers/staff members, the less likely students are to commit offenses that lead to suspension. Interventions that focus on strengthening teacher-student relationships can reduce the use of exclusionary discipline (Skiba \& Losen, 2015). This is shown in the use of restorative practices by schools where building positive relationships and trying to repair broken relationships is the focus (Skiba \& Losen, 2015). School culture and climate improve when school wide positive behavior intervention programs are implemented. All student

participants in my study overwhelmingly agreed that relationships with school personnel are very important.

For a large number of at-risk youths, being suspended leads to other problems outside of school, increases the likelihood of receiving additional out of school suspensions (OSS) and may result in dropping out of school (Dupper, Theriot, \& Craun, 
2009; Breunlin, D., et al. 2002). When students are suspended out of school, there is often no adult supervision at home, resulting in an increased opportunity to engage in crimes in the community (Cuellar \& Markowitz, 2015). Students who have experienced out-of-school suspension are more than eight times as likely to be incarcerated as those who graduate from high school (Castillo, 2013). When students in my study were asked if they had gotten into additional trouble when suspended, the student participants agreed that the potential to get in trouble with the law was much greater for students suspended out of school.

\section{Implications for School Leaders}

Instead of relying so heavily on the exclusionary measure of out of school suspension, high schools need discipline practices that improve long term student outcomes (Flannery et al., 2014). This study showed how students' perceive the negative impact of out of school suspension on academic motivation. Students felt that out of school suspensions lessened their chances for academic success. This research could pave the way for new discipline policies. Schools are mandated by the No Child Left behind Act of 2001 to develop disciplinary policies and codes of conduct (Fenning et al., 2012). These policies are to describe the responsibilities of all students and the consequences when behavior violations occur. If the policies do not take into consideration what research has shown, the same issues will occur with exclusionary discipline. Based on school year 2009-2010, federal data confirms that middle and high school students are being suspended out of school for minor offenses, even though exclusionary discipline policies used on students who have a positive view of school may actually serve to disengage them and place them at risk for poor adaptation (Morrison et al., 2001). These policies do not take into consideration why events occur, what the 
reasons for the student's involvement are, and any history which may have attributed to the behavior (Kang-Brown et al., 2013; Skiba, 2000). A wider network of good students are being caught in the web of suspensions which could lead to students perceiving they are being betrayed by school staff.

Student participants in this study made suggestions for many alternatives to out of school suspension. In school suspension was one alternative that students suggested. They felt that at the very least the student would not be unsupervised and would be given the opportunity to get their school work in order for them to not be as behind in their work. Another suggestion was more support staff to help students with home/school issues. They also felt that preventive measures would help such as school-wide behavior intervention activities.

An alternative that I am very passionate about that the school district in my study has introduced but not implemented with fidelity (according to the student responses during the interviews) is Restorative Justice. This falls in line with all of the suggestions students had for alternatives to suspension. In chapter two, Restorative Justice was introduced as a successful disciplinary approach that focuses on restoring relationships and repairing harm and developing student's social and emotional competencies (Morrison, 2003). The key for any new system is that it has to be implemented with fidelity. This begins with a review of staff language. Staff language must move away from terms associated with criminal activity including crime, victim, offense, and punishment and embrace restorative language of violation, harm, and accountability. The focus moves away from punitive consequences to repair of property and restoration of relationships. Discipline decisions are made together with the harmed individuals and 
community members. A mediation/restorative circle can be used proactively, to develop or reactively, respond to conflicts. The circles give people an opportunity to share and listen to each other in a safe, equitable environment (Pranis, 2005). David Yusem (2013, p.2, Program Manager of Restorative Justice for the Oakland Unified School District, states: "the circles are based on indigenous practices that value inclusiveness, respect, dealing with things as a community and supporting healing" student discipline practices move away from issuing sanctions to and against a student toward sanctions occurring with and for students accompanied with school community members (Costello, Wachtel \& Wachtel, 2009). Staff members work to identify the harm, involve stakeholders, and ensure accountability. It is essential that students understand how behavior impacts the school community and their membership in the community is a priority.

Highly successful implementations of programs occurred when those that initiated the program were deeply committed and were able to provide time and resources (Fowler, 2013). Revised codes of conduct create a need to provide school staff effective training on positive behavior intervention programs and supports to implement those (Skiba \& Losen, 2015). Each school has to make it a priority to provide professional development for the program that is chosen. Ongoing coaching and consultation are required to support teachers with implementation of any school-wide behavior and intervention plan. Fidelity of implementation cannot be assured without coaching and continuous progress monitoring.

From the participants' answers to the semi-structured interview questions, there was no indication that Restorative Justice was being implemented. Student suggestions reflected what restorative justice is all about. Again, it is imperative that these new 
school/district wide behavior prevention/intervention programs be implemented with fidelity and consistency. We do need to actively listen more to our students. They are telling us what they need to be successful.

School leaders do have a legal obligation to keep schools safe. All schools are not created equal in terms of effectiveness of program implementation. What works in one school may not work in another. The reliance on administrators to work with stakeholders to facilitate the process of identifying the best fit for their school is imperative when developing discipline policies. The foundation of policy influence is based on building relationships beyond the school to include government officials who have an impact on education policy in a certain school or district (Fowler, 2013). To provide more constructive alternatives to exclusionary discipline policies, district, state and federal policy makers have to work together to provide alternative programs. These programs must promote productive and healthy climates without depriving certain numbers of students the opportunity to learn (Skiba \& Losen, 2015).

\section{Recommendations for Future Research}

According to Noltemeyer et al., (2015), more research is needed on factors that identify the relationships between suspension and outcomes. This study did not take into consideration the connection to other factors that could potentially be part of the impact on academic motivation as well as out of school suspension. Other studies could be conducted to show how other factors such as race, gender, and socioeconomic status might affect academic motivation. Students in this study were chosen from two of the lowest performing schools in the district. This study could be replicated in other schools to further establish a connection between out of school suspension and the impact on academic motivation. 
An opportunity for future research might entail a follow-up with the same student group from this study after the implementation of restorative practices or conducting a post graduate follow-up with the same students in two years. Another possibility for future research involves implementing restorative practices at the elementary or middle school level to see if the suspension rate is impacted.

\section{Reflection of the Researcher}

These student participants were extremely appreciative of the opportunity to be given a voice to share their thoughts and feelings about this very important issue. Educators have to develop a base of trust with students and parents. Some students immediately put up walls. Every student has a story and some stories are not good. All students felt that the development of relationships with school staff were extremely important to their academic motivation. All the more reason to develop school wide behavior prevention/intervention programs that primarily focus on relationship building.

\section{Closing}

As Durkheim (1973) clarified decades ago, the foundation of effective discipline lies in the achievement of "moral authority" based on trust, affirmation, and caring relationships. As a researcher, this is that one statement that sums everything up with such powerful words. It is then backed up by the findings of this study. Trust, affirmation and caring relationships are imperative in the school environment for students to be successful. Not only do we have moral authority but we, as educators, have a moral obligation to our students to be treated fairly. 


\section{REFERENCES}

Allman, K. L., \& Slate, J. R. (2011). School discipline in public education: A brief review of current practices. International Journal of Educational Leadership Preparation, 6(2).

Anderson, K., Ritter, G., \& Zamarro, G. (2017). Understanding a vicious cycle: Do out of-school suspensions impact student test scores?

Anyan, F. (2013). The Influence of Power Shifts in Data Collection and Analysis Stages: A Focus on Qualitative Research Interview. Qualitative Report, 18, 36.

Arcia, E. (2006). Achievement and enrollment status of suspended students: Outcomes in a large, multicultural school district. Education and Urban Society, 38(3), 359369.

Arcia, E. (2009). A comparison of elementary/k-8 and middle schools" suspension rates. Urban Education, 42, 456-469.

Arum, R., (2003). Judging school discipline: The crisis of moral authority. Cambridge, MA: Harvard University Press.

Ayers, W., Dohrn, B., \& Ayers, R. (2001). Zero tolerance: resisting the drive for punishment in our schools. A Handbook for Parents, Students, Educators, and Citizens. New Press, New York, NY.

Baker-Smith, E., \& Lipschultz, J. "Do alternatives matter: Is the provision of disciplinary alternatives associated with lower levels of low level suspensions in 
american high schools?" Sociological Studies of Children and Youth, 20, 281 290.

Balfanz, R., Bridgeland, J. M., Bruce, M., \& Fox, J. H. (2013). Building a Grad Nation: Progress and Challenge in Ending the High School Dropout Epidemic. Annual Update, 2013. Civic Enterprises.

Balfanz, R., Byrnes, V., \& Fox, J. H. (2015). Sent home and put off track. closing the school discipline gap: Equitable remedies for excessive exclusion, 17-30. New York, NY.

Barnes, J., Conrad K., Demont-Heinrich, C., Graziano,M., D., Kowalski, Neufeld, J., Zamora, J., \& Palmquist, M. (2012). Generalizability and Transferability. Writing@CSU. Colorado State University. Available at https://writing.colostate.edu/guides/guide.cfm?guideid=65.

Barrett, N., McEachin, A., Mills, J. N., \& Valant, J. (2017). Disparities in student discipline by race and family income.

Beachum, F. D., Dentith, A., McCray, C. R., Boyle, T. (2008). Havens of hope or the killing fields: the paradox of leadership, pedagogy, and relationships in an urban middle school. Urban Education. (43)2, 189-215.

Beachum, F. D. \& McCray, C. R. (2011). Cultural collision and collusion: Reflections on hip-hop, culture, value, and schools. New York: Peter Lang.

Bechtold, J., Cauffman, E., Monahan, K. C., \& VanDerhei, S., (2014). From the school yard to the squad car: school discipline, truancy, and arrest. Journal of Youth Adolescence, 43, 1110-1122.

Bergquist, C. C., Bigbie, C. L., Groves, L., \& Richardson, G. H. (2004). Evaluation 
report for the study of alternatives to suspension. Tallahassee, FL: Evaluation Systems Design.

Blomberg, N. (2003). Effective discipline for misbehavior: In-school versus out-ofschool Suspension. Concept, 27.

Bloomberg, K., West, D., \& Johnson, H. (2004). InterAACtion: Strategies for intentional and unintentional communicators. Communication Resource Centre SCOPE.

Bottiani, J. H., Bradshaw, C., P., \& Mendelson, T. (2017). A multilevel examination of racial disparities in high school discipline: black and white adolescents' perceived equity, school belonging, and adjustment problems. Journal of Educational Psychology, 109(4), 532-545.

Breunlin, D. C., Cimmarusti, R. A., Bryant-Edwards, T. L., \& Hetherington, J. S. (2002). Conflict resolution training as an alternative to suspension for violent behavior. The Journal of Educational Research, 95(6), 349-357.

Bruns, E. J., Moore, E., Stephan, S. H., Pruitt, D., \& Weist, M. D. (2005). The impact of mental health services on out-of-school suspension rates. Journal of Youth and Adolescence, 34(1).

Cameron, M. (2006). Managing school discipline and implications for school social workers: A review of the literature. Children \& Schools, 28(4), 219-227.

Casey, M. A. \& Krueger, R. A., (2002). Designing and conducting focus group interviews. Social analysis, selected tools and techniques, 4(23), 4-24.

Castillo, J. (2013) Tolerance in schools for Latino students: Dismantling the school-to prison pipeline. Harvard Journal of Hispanic Policy, (26), 43-58.

Chadwick, B. Gill, P., Stewart, K., \& Treasure, E., (2008). Methods of data collection in 
qualitative research: interviews and focus groups. British Dental Journal, 204(6), 291-295.

Cobb-Clark, D.A., Kassenboehmenr, S. C., Le, T., McVicar, D., \& Zhang, R. (2015). Is there an educational penalty for being suspended from school? Education Economics, 23(4), 376-395.

Cohen, L. E., \& Felson, M. (2016). Social Change and Crime Rate Trends: A Routine Activity Approach (1979). In Classics in Environmental Criminology (pp. 203 232). CRC Press.

Committee on School Health. (2003). Out-of-school suspension an expulsion. Pediatrics, 112(5), 1206-1209.

Cook, C. R., Williams, K. R., Guerra, N. G., Kim, T. E., \& Sadek, S. (2010). Predictors of bullying and victimization in childhood and adolescence: A meta-analytic investigation. School psychology quarterly, 25(2), 65.

Cook, P. J., Gottfredson, D. C., Na, C. (2010). School crime control and prevention. In: Tonry, M., (Ed.). Crime and Justice: A Review of Research. University of Chicago Press, Chicago.Corbin, J., \& Strauss, A. L. (2008). Basics of qualitative research (3e éd.). Thousand Oaks.

Cornell, D. G., Allen, K., \& Fan, X. (2012). A randomized controlled study of the Virginia Student Threat Assessment Guidelines in kindergarten through grade 12. School Psychology Review, 41(1), 100.

Costenbader, V., \& Markson, S. (1998). School suspension: A study with secondary school students. Journal of School Psychology, 36(1), 59-82. 
Costello, B., Wachtel, J., \& Wachtel, T. (2009). The Restorative Practices Handbook International Institute for Restorative Practices, Bethlehem, PA.

Creswell, J. W. (2003). Mixed method procedures in research design: Qualitative, quantitative, and mixed method approaches (2nd ed.) (pp. 208-225). Thousand Oaks, CA: Sage Publications.

Creswell, J. W. (2005). Educational research, planning, conducting, and evaluating quantitative and qualitative research. Prentice Hall.

Creswell, J. W. (2005). Mixed method designs in educational research: Planning, conducting, and evaluating quantitative and qualitative research (2nd ed.). (pp. 510-530). Upper Saddle River, NJ: Pearson Merrill Prentice Hall.

Creswell, J. W., Hanson, W. E., Clark Plano, V. L., \& Morales, A. (2007). Qualitative research designs: Selection and implementation. The Counseling Psychologist, 35(2), 236-264.

Creswell, J. W. (2013). Research design: Qualitative, quantitative, and mixed methods approaches. Sage publications.

Creswell, J. W. (2014). A concise introduction to mixed methods research. Sage Publications.

Crotty, M. (1998). The foundations of social research: Meaning and perspective in the research process. Sage.

Cuellar, A. E., \& Markowitz, S. (2015). School suspension and the school-to-prison pipeline, International Review of Law and Economics, 43, 98-106.

Daunic, A. P., Smith, S. W., Rowand Robinson, T., Miller, M. D., \& Landry, K. L. 
(2000).School-wide conflict resolution and peer mediation programs: Experiences in three middle schools. Intervention in School and Clinic, 36(2), 94-100.

Dictionary, C. E. (2014). CED. Complete \& Unabridged.

Dupper, D. R., \& Bosch, L. A. (1996). Reasons for School Suspensions. Journal for a Just and Caring Education, 2(2), 140-50.

Dupper, D., Theriot, M.T., \& Craun, S. (2009). Reducing out-of-school suspensions: Practice guidelines for school social workers, Children \& Schools,31(1), 6-14.

Durkheim, Emile. (1973). Moral Education. New York: Macmillan.

Ekstrom, R. B., Goertz, M. E., Pollack, J.M., \& Rock, D. A., (1986). Who drops out of high school and why? Findings from a national study. Teachers College Record, 87, 357-373.

Epstein, J. L., Galindo, C. L., \& Sheldon, S. B. (2011). Levels of leadership: Effects of district and school leaders on the quality of school programs of family and community involvement. Educational Administration Quarterly, 47(3), 462-495.

Fabelo, T., Thompson, M. D., Plotkin, M., Carmichael, D. Marchbanks, M. P. I., \&

Booth, E. A. (2011). Breaking school's rules: A statewide study of how school discipline relates to students' success and juvenile justice involvement. New York, NY: Council of State Governments Justice Center.

Fenning, P.A., Pulaski, S., Gomez, M., Morello, M., McArdle, I, Morello, E., et al. (2012). Call to action: A critical need for designing alternatives to suspension and expulsion, Journal of School Violence, 11, 105-117.

Finn, J. D., \& Servoss, T. J. (2013). Misbehavior, Suspensions, and Security Measures in 
High School: Racial/Ethnic and Gender Differences. Paper presented at the Closing the school discipline gap: Research to practice, Washington, DC.

Flannery, K.B., Fenning, P., Kato, M., McIntosh, K. (2014). Effects of school-wide positive behavioral intervention and supports and fidelity of implementation on problem behavior in high schools. School Psychology Quarterly, 29(2), 111-124.

Flynn, R.M., Lissy, R., Alicea, S., Tarzartes, L., \& McKay, M.M. (2016). Professional development for teachers plus coaching related to school-wide suspensions for a large scale urban school system. Children and Youth Services Review, 62, 29-39.

Foote, M. Q., \& Bartell, T. G. (2011). Pathways to equity in mathematics education: How life experiences impact researcher positionality. Educational Studies in Mathematics, 78(1), 45-68.

Fowler, F. (2013). Policy Studies for Educational Leaders: An Introduction. $\left(4^{\text {th }}\right.$ ed). New York: Pearson.

Garland, D., (2001). The Culture of Control: Crime and Social Order in Contemporary Society, Chicago: University of Chicago Press.

Gasson, S. (2004). Rigor in grounded theory research: An interpretive perspective on generating theory from qualitative field studies. In M. E. Whitman \& A. B. Woszczynski (Eds.), The handbook of information systems research (pp. 79-102). Hershey, PA: Idea Group. G

George, H., Harrower, J. \& Knoster, T. (2003). School-wide prevention and early intervention: A process for establishing a system of school-wide behavior support. Preventing School Failure, 47(4), 170-176. 
Gibson, P., Wilson, R., Haight, W., Kayama, M. \& Marshall, J. (2014). The role of race in the out-of-school suspensions of black students: the perspectives of students with suspensions, their parents and educators. Children and Services Review, 47, 274-282.

Gibson, P. A., \& Haight, W. (2013). Caregivers' moral narratives of their African American children's out-of-school suspensions: Implications for effective familyschool collaborations. Social work, 58(3), 263-272.

Glesne, C. (2015). Becoming qualitative researchers: An introduction. Pearson.

Golafshani, N. (2003). Understanding reliability and validity in qualitative research. The Qualitative Report, 8(4), 597-606.

Gowdey, Logan J. (2015). Disabling discipline: locating a right to representation of students with disabilities in the ADA, Columbia Law Review; New York, 115(8), 2265-2309.

Gregory, J. F., Three strikes and they're out: African american boys and american schools' responses to misbehavior. International Journal of Adolescence and Youth, 7, 25-34. http://dx.doi.org/10.1080/02673843.1997.9747808.

Hall, S. (2000). New Ethnicities (1988). Writing Black Britain 1948-1998: An Interdisciplinary Anthology, 265.

Hirschfield, Paul J. (2008). "Preparing for Prison? The Criminalization of School Discipline in the USA.” Theoretical Criminology 12(1), 79-101.

Jordan, J. L. \& Anil, B. (2009). Race, gender, school discipline, and human capital effects. Journal of Agricultural and Applied Economics; Baton Rouge, ${ }_{\square} 41(2)$, 419-429. 
Hirschfield, P. (2010). 'School Surveillance in America (pp. 38-54). New Brunswick: Rutgers University Press.

Hycner, R. H. (1985). Some guidelines for the phenomenological analysis of interview data. Human studies, 8(3), 279-303.

Jordan, J. L., \& Anil, B. (2009). Race, gender, school discipline, and human capital effects. Journal of Agricultural and Applied Economics, 41(2), 419-429.

Kang-Brown, J., Trone, J., Fratello, J., Daftary-Kapur, T. (2013). Issue brief: A generation later. what we've learned about zero tolerance in schools. Vera Institute of Justice, New York, http://www.vera.org/sites/default/files/resources/downloads/zero-tolerancein-schools-policy-brief.pdf.

Kemp, L., \& Hall, A. H. (1992). Impact of Effective Teaching Research on Student Achievement and Teacher Performance: Equity and Access Implications for Quality Education.

Kessel, F., \& Norman Anderson American Psychological Association (Eds.). (2008). Interdisciplinary Research: Case Studies from Health and Social Science: Case Studies from Health and Social Science. Oxford University Press, USA.

Kirkman, C. J., McNees, H., Stickl, J., Banner, J. H., \& Hewitt, K. K. (2016). Crossing the suspension bridge: Navigating the road from school suspension to college success-how some students have overcome the negative implications of school suspension to bridge the road to college. Journal of Organizational and Educational Leadership, 2(1) n1.

Knesting, K. (2008). Students at risk for school dropout: supporting their persistence. 
Preventing School Failure, 52, (3-10).

Krezmien, M. P., Leone, P.E., \& Achilles, G. M. (2006). Suspension, race and disability: Analysis of statewide practices and reporting. Journal of Emotional and Behavioral Disorders, 14 217-226.http://dx.doi.10.1177/10634266060140040501.

Krueger, R. A., \& Casey, M. A. (2002). Designing and conducting focus group interviews.

Kupchik, A., \& Monahan, T. (2006). The new american school: Preparation for post industrial discipline. British Journal of Sociology of Education, 27, 617-632.

Kupchik, A., \& Catlaw, T. J. (2013). Discipline and Participation: The Long--Term Effects of Suspension and School Security on the Political and Civic Engagement of Youth. Paper presented at the Closing the school discipline gap: Research to practice, Washington, DC.

Lamont, J. H., Devore, C. D., Allison, M., Ancona, R., Barnett, S. E., Gunther, R., \& Young, T. (2013). Out-of-school suspension and expulsion. Pediatrics, 131(3), e1000-e1007.

Lipton, D., Martinson, R., \& Wilks, J. (1975). The Effectiveness of Correctional Treatment: A Perry and Morris 1087 Survey of Treatment Evaluation Studies. New York: Praeger.

Losen, D. J. \& Martinez, T. E. (2013). Out of school and off track: The overuse of suspensions in american middle and high schools, Executive Summary, The Center for Civil Rights Remedies.

Losen, D., Hodson, C., Keith, M. A., Morrison, K., \& Belway, S. (2015). Are we closing 
the school discipline gap? Los Angeles, CA: The Center for Civil Rights Remedies at the Civil Rights Project, University of California, Los Angeles. Retrieved from http://civilrightsproject.ucla.edu/resources/projects/center-for-civil-rights-/schoolto-prison-folder/federal-reports/are-we-closing-the-school-disciplinegap/AreWeClosingTheSchoolDisciplineGap_FINAL221.pdf.

Losen, D. J. (2011). Discipline Policies, Successful Schools, and Racial Justice. Boulder, $\mathrm{CO}$.

Losen, D. J. (2013). Out of school and off track: The overuse of suspensions in american middle and high schools, Executive Summary, The Center for Civil Rights Remedies.

Mallette, D. (2012). National Education Policy Center. Dropping out: Why students drop out of high school and what can be done about it. Journal of Family and Consumer Sciences; Alexandria ${ }_{\Xi} 104(3){ }_{,}$51-52.

Mallette, C. A. (2016). The school to prison pipeline: A critical review of the punitive paradigm shift. Child Adolescent Social Work Journal, 33(1), 15-24.

Marchbanks III, M. P., Blake, J., Booth, E. A., Carmichael, D., Seibert, A. L., \& Fabelo, T. (2013). The economic effects of exclusionary discipline on grade retention and high school dropout. Paper presented at the Closing the school discipline gap: Research to practice, Washington, DC.

Mauer, M., Chelsey-Lind, M. eds. (2002). Invisible Punishment: The collateral consequences of mass imprisonment. New York: The Free Press.

Mendez, L. M. R., \& Knoff, H. M. (2003). Who gets suspended from school and why: A 
demographic analysis of schools and disciplinary infractions in a large school district. Education and Treatment of Children, 30-51.

Milner IV, H. R. (2007). Race, culture, and researcher positionality: Working through dangers seen, unseen, and unforeseen. Educational researcher, 36(7), 388-400.

Milner, J., Myers, S., \& O'Byrne, P. (2015). Assessment in social work. Macmillan International Higher Education.

Monahan, K. C., VanDerhei, S., Bechtold, J., \& Cauffman, E. (2014). From the school yard to the squad car: school discipline, truancy, and arrest. Journal of Youth Adolescence, 43, 1110-1122.

Morrison, B. (2013). Restorative justice in schools. In New directions in restorative justice (pp. 50-76). Willan.

Morrison, G. M., Anthony, S., Storino, M. H., Cheng, J. J., Furlong, M. J., \& Morrison, R. L. (2001). School expulsion as a process and an event: Before and after effects on children at risk for school discipline. New Directions for Mental Health Services, 92, 45-71.

Morrow, S. L. (2005). Quality and trustworthiness in qualitative research in counseling psychology. Journal of Counseling Psychology, 52(2), 250.

Moser, S. (2008). Personality: a new positionality?. Area, 40(3), 383-392.

Nation, M., Crusto, C., Wandersman, A., Kumpfer, K. L., Seybolt, D., Morrissey-Kane, E., \& Davino, K. (2003). What works in prevention: Principles of effective prevention programs. American Psychologist, 58(6-7), 449.

Noble, H., \& Smith, J. (2015). Issues of validity and reliability in qualitative 
research. Evidence-Based Nursing, ebnurs-2015.Noltemeyer, A. L., Ward, R. M., \& McLoughlin, C. (2015). Relationship between school suspension and student outcomes: A meta-analysis, School Psychology Review 44(2), 224-240.

Noltemeyer, A. L., Ward, R. M., \& Mcloughlin, C. (2015). Relationship between school suspension and student outcomes: A meta-analysis. School Psychology Review, 44(2), 224-240.

Osher, D., Morrison, G., \& Bailey, W. (2003). Exploring the relationship between student mobility and dropout among students with emotional and behavioral disorders. Journal of Negro Education, 79-96.

Perry, B. \& Morris, E (2014). Suspending progress: collateral consequences of exclusionary punishment in public schools. American Sociological Review, 79(6), 1067.

Planty, M., Hussar, W., Snyder, T., Kena, G., KewalRamani, A., Kemp, J., Bianco, K., Dinkes, R. (2009). The Condition of Education 2009 (NCES 2009-081). National Center for Education Statistics, Institute of Education Sciences, U.S. Department of Education. Washington, DC.

Porowski, A., O'Connor, R., \& Passa, A. (2014). Disproportionality in school discipline: An assessment of trends in maryland, 2009-12. Regional Educational Laboratory Mid-Atlantic, U.S. Department of Education. Retrieved from https://ies.ed.gov/ncee/edlabs/regions/midatlantic/pdf/REL_2014017.pdf.

Pranis, K. (2005). A cry for love.

Raffaele Mendez, L. M., \& Knoff, H. M. (2003). Who gets suspended from school and 
why: a demographic analysis of schools and disciplinary infractions in a large school district. Education and Treatment of Children, 26(1), 30-51.

Rausch, M. K., \& Skiba, R. (2004). Unplanned outcomes: Suspensions and expulsions in indiana. Education Policy Briefs, 2(2), 1-8.

Roggla, G., Moser, B., \& Roggla, M. (2008). Suspension trauma. Emergency Medicine Journal, 25(1), 59-59.

Rumberger, R. (2011). Solving the nation's dropout crisis. Education Week, 31(9), 24-28.

Saldaña, J. (2016). Ethnotheatre: Research from page to stage. Routledge.

Seay, T. M. (2015). The relationship between administrators' implicit attitudes about race and local school suspension rates for African American students. Mercer University.

Schools, J. C. P. (2016). Student Support and Behavior Intervention Handbook.

Semke, C. A., Garbacz, S. A., Kwon, K., Sheridan, S. M., \& Woods, K. E. (2010). Family involvement for children with disruptive behaviors: The role of parenting stress and motivational beliefs. Journal of School Psychology, 48(4), 293-312.

Sharkey, J. D., \& Fenning, P. A. (2012). Rationale for designing school contexts in support of proactive discipline. Journal of School Violence, 11(2), 95-104.

Shollenberger, T. L. (2013). Racial disparities in school suspension and subsequent outcomes: Evidence from the national longitudinal survey of youth 1997. Paper presented at the Closing the school discipline gap: Research to practice, Washington, DC.American Educational Research Journal, 51(4), 640-70.

Skiba, R. J., Chung, C. G., Trachok, M., Baker, T. L., Sheya, A., \& Hughes, R. L. (2014). 
Parsing disciplinary disproportionality: Contributions of infraction, student, and school characteristics to out-of-school suspension and expulsion. American Educational Research Journal, 51(4), 640-670.

Skiba, R. J., Arredondo, M. I., \& Rausch, M. K. (2014). New and developing research on disparities in discipline. Bloomington, IN: The Equity Project at Indiana University.

Skiba, R. J., Horner, R. H., Chung, C. G., Rausch, M. K., May, S. L., \& Tobin, T. (2011). Race is not neutral: A national investigation of African American and latino disproportionality in school discipline. School Psychology Review, 40(1), 85-107.

Skiba, R. J. (2000). Zero tolerance, zero evidence. An analysis of school disciplinary practice. $2-22$.

Skiba, R. J., Michael, R. S., Nardo, A. C., \& Peterson, R. (2002). The color of discipline: Sources of racial and gender disproportionality in school punishment. Urban Review, 34, 317-342.

Skiba, R. J., \& Losen, D. J. (2015). From reaction to prevention: Turning the page on school discipline. American Educator, 39(4), 4.

Skiba, R \& Peterson, R. (2003). Teaching the social curriculum: school discipline as instruction. Preventing School Failure, 47(2), 66-73.

Skiba, R., Reynolds, C. R., Graham, S., Sheras, P., Conoley, J. C., Garcia-Vazquez, E., \& Edmiston, A. (2006). Are zero tolerance policies effective in the schools? An evidentiary review and recommendations. An official report of the APA.

Smith, R. Y. (2015). A review of Prelude to Prison: Student Perspectives on School Suspension. Journal of Pan African Studies, 8(3), 136-140. 
Smith, E. J., \& Harper, S. R. (2015). Disproportionate impact of K-12 school suspension and expulsion on Black students in southern states. Center for the Study of Race and Equity in Education. Philadelphia, PA: University of Pennsylvania. Retrieved from http://www.gse. upenn. edu/equity/sites/gse.upenn.edu. equity/files/publications/SOUTHADVANCEDDRAFT24AUG15. pdf.

Stader, D. L. (2004). Zero tolerance as public policy: The good, the bad, and the ugly. The Clearing House: A Journal of Educational Strategies, Issues and Ideas, 78(2), 62-66.

Steinberg, M. P., Allensworth, E., \& Johnson, D. W. (2013). What conditions jeopardize and support safety in urban schools? The influence of community characteristics, school composition and school organizational practices on student and teacher reports of safety in Chicago.

Stormont, M., Reinke, W. M., Newcomer, L., Marchese, D., \& Lewis, C. (2015). Coaching teachers' use of social behavior interventions to improve children's outcomes: A review of the literature. Journal of Positive Behavior Interventions, $17(2), 69-82$.

Suh, S., Suh, J., Houston, I. (2007). Predictors of categorical at-risk high school dropouts. Journal of Counseling and Development, 85(2), 196-203.

Taras, H. L., Frankowski, B.L., McGrath, J. W., Mears, C. J., Murray, R. D., \& Young, T. L. (2003) Committee on School Health. (2003). Out-of-school suspension and expulsion. Pediatrics, 112(5), 1206-1209.

Triplett, N. P., Allen, A., \& Lewis, C. W. (2014). Zero tolerance, school shootings, and 
the post-brown quest for equity in discipline policy: An examination of how urban minorities are punished for white suburban violence. The Journal of Negro Education, 83(3), 352-370.

Vincent, C. G., Swain-Bradway, J., Tobin, T. J., \& May, S. (2011). Disciplinary referrals for culturally and linguistically diverse students with and without disabilities: Patterns resulting from school-wide positive behavior support. Exceptionality, 19(3), 175-190.

Wallace Jr, J. M., Goodkind, S., Wallace, C. M., \& Bachman, J. G. (2008). Racial, ethnic, and gender differences in school discipline among US high school students: 19912005. The Negro Educational Review, 59(1-2), 47.

Waters, J. (2013). Phenomenological research guidelines. Retrieved December, 7, 2013. https://www.capilanou.ca/.../Phenomenological-Research-Guidelines

Wahlage, G., \& Rutter, R. (1986). Evaluation of model program for at-risk students. In annual meeting of the American Educational Research Association, San Francisco, CA.

Western, B. (2006). Punishment and Inequality in America. New York: Russell Sage. 


\section{APPENDIX A \\ Semi-structured Interview Questions}

1.) What does it feel like to be suspended from school?

2.) What did you do while you were suspended from school?

3.) Was anyone at home with you while you were suspended?

4.) How did you parent/guardian react to your suspension from school?

5.) How did you learn the material you missed while you were out?

6.) If you had to describe how you felt being suspended from school in one word, what would it be?

7.) Did you look forward to coming back to school? Why or why not?

8.) Have you ever gotten into trouble while on suspension? If yes, were police involved and what type of offense?

9.) How do you think being suspended affected your grades?

10.) How do think other students treat you when you return to school?

11.) Do you feel out of school suspensions work to help students with their behavior? Why or why not?

12.) If you feel out of school suspensions do not work, what suggestions for alternatives do you have?

13.) How important are the relationships with adults in the school building to you?

Do you feel like the adults in the building care about you? 
14.) Do you feel like you "fit in" with your school community? Why or why not?

15.) How can schools do a better job of helping students make better behavior choices? 


\section{APPENDIX B \\ Parent Permission Letter}

Dear Parent/Guardian,

My name is Dawn Roseberry and I am a doctoral student in the School of Educational Leadership and Development at the University of Louisville. I am also employed as a Guidance Counselor for Jefferson County Public Schools. I am conducting a research study about student perception of out of school suspension on academic motivation and how the severity of the offenses leading to suspension may impact the student's perception of how this affects their academic motivation. I am interested in your child's perception because they have been suspended six or more days this school year.

I am seeking permission for your child to participate in a semi-structured interview. The semi-structured interview questions will contain questions relating to academic achievement, activities when suspended, feelings upon return to school, perceptions of support from school and home, and suggestions for alternatives to out of school suspensions. All information will be kept confidential and your child's identity will not be revealed to anyone.

Your child has an important role in this research. The data collected may help modify future discipline policies to help students. As a participant in this study, there will 
be no discomfort except what is experienced during daily life activities. There is no direct benefit or harm to your child through this study. There is no cost to participate and no compensation for participating.

All data collected pertaining to this research study will be kept confidential. All participants will be audiotaped during the focus group. The use of this audiotape will only be used to collect data relating to the research study. Participation is strictly voluntary. There is no impact to your student's grades or class standing.

If you are granting permission for your child to participate in this study, please sign below. If you have any questions, please contact me at dawn.roseberry@_ or on my cell phone at (502) 548-4702. Parent/Guardian Signature:

Date: 


\section{APPENDIX C}

\section{Student Letter}

Dear student,

Your parent/guardian has given permission for you to participate in a research study. I would like to explain more about this process so that you know what to expect.

My name is Ms. Roseberry and I am a guidance counselor in a high school. I am also a doctoral student in the School of Educational Leadership and Development at the University of Louisville. In order to graduate, I am conducting a research study to see what students' have to say about being suspended out of school. I would like to hear about how you think this affects your motivation to succeed in school. Because you have experienced being suspended out of school for six or more days this year, I think what you have to say could be very important in the way schools handle behavioral issues in the future.

You will be part of a group of students called a focus group who have been invited to participate. Questions will be asked relating to academic achievement, activities when suspended, feelings upon return to school, perceptions of support from school and home, and suggestions for alternatives to out of school suspensions. All information will be kept confidential. No real names will be given when reviewing the information collected during the focus groups. You will receive a summary of what was discussed in the focus groups to make sure it is correct. Your input is very important to 
the success of my study and may impact school discipline policies for the future. Thank you for considering this invitation to share your experiences and the way it has impacted your academic motivation.

Sincerely,

Ms. Roseberry 


\section{APPENDIX D}

\section{Principal Communications}

Hello Principal of Aaron High School! My name is Dawn Roseberry and I am one of the Guidance Counselors at Fern Creek High School. I am currently working on my dissertation I spoke to Dr. Marco Munoz and he suggested I contact you to ask about using some of your students in my focus groups. My topic is out of school suspension and my research questions are: How do students perceive out of school suspensions' impact on their academic motivation? Do their perceptions change based on the severity of the offense(s)? It is the hope of this researcher that this study will help yield understanding about the impact of out of school suspensions on students. Student voice can help educators in the development of more effective school discipline policies. I am also going to use Lucas High School as my other school. I would like to conduct two focus groups per school, one with six-eight students who have six or more days of suspension for lesser offenses and one group of six-eight students who have been suspended six or more days for harsher offenses (non-negotiables). I would not be identifying the schools in the study or the district. This information will only be used to help identify perception of how out of school suspension affects student academic performance. I will share all findings with you before submitting data and even do a future presentation to staff if you would like. I will do whatever it takes to gain your approval. Thanks for any consideration. I am happy to meet with you to discuss 
methodology further. My number is and my email

is 


\title{
CURRICULUM VITA
}

\author{
Dawn B. Roseberry \\ 9819 STANALOUISE DRIVE, LOUISVILLE, KY 40291 \\ PHONE (502) 548-4702 E-MAIL DAWN.ROSEBERRY@JEFFERSON.KYSCHOOLS.US
}

\section{EDUCATION}

1987 B.A. Counseling Psychology, University of Louisville

1996 M.Ed. Counseling Psychology, University of Louisville

2013 M.Ed. School Guidance Counseling, Spalding University

2015-present Doctoral student, Educational Leadership and Organizational

Development, University of Louisville

PROFESSIONAL EXPERIENCE

2015-present: Adjunct Professor, Spalding University

2013-present: School Guidance Counselor, Jefferson County Public Schools - Fern

Creek High School.

- Member of school leadership team

- Responsible for helping students develop a plan for academic success with a focus on a career pathway.

1999-2013: Youth Services Center Coordinator, Jefferson County Public Schools -

Fern Creek Traditional High School and Carrithers Middle School

- Responsible for helping students and families at both schools overcome obstacles to academic success. This is accomplished through various programs and interventions. Based on needs assessments taken by students, parents and staff members and state mandated components, services are offered to address identified needs.

1989-1999: Career Planner, Jefferson County Public Schools- Iroquois High School, Eastern High School, and Fern Creek High School.

- Responsible for carrying a case load of 60 students that met certain criteria that qualified them for extra support. The goal was to help them achieve academic success throughout their high school career.

1982-1989: Personnel Manager, Target Retail Stores, Louisville, Started as a part-time cashier working up to Cashier Supervisor and then to Personnel Manager.

- After becoming a Personnel Manager, was then promoted from a store with 120 employees to a higher volume store with 170 employees. 


\section{COMMUNITY INVOLVEMENT}

- 2003-present, Member of St. Edwards Catholic Church

- 2000-present, Volunteer at Fern Creek/Highview United Ministries

- 2000 -2013, Metro United Way representative for employee campaign at Fern Creek High School

- 2000 -2013, Representative for American Red Cross - organize two blood drives per year

\section{PROFESSIONAL ORGANIZATIONS}

- 2003 - 2012, Fern Creek Community Association

- 2003 - present, Jefferson County Public Schools Administrators Association

- 2003 - 2012, Interview/Screening Committee for JCPS Family Resource Youth Services Centers

- 2001 - 2012, Family Resource Youth Services Centers Coalition

- 2012 - present, Kentucky School Counselor Association

- 2012 - present, American Counseling Association

\section{AWARDS, PRESENTATIONS, PROPOSALS}

- 2016-Present, Organized mentoring program called, "The Creek Sisters" for female students. Upperclassmen mentored underclassmen girls to help with the high school journey

- 2016- Present, Helped write proposal for a program called, CLAWS (Creek Leadership Always Watching Students) to help struggling students with grades, attendance, organizational strategies and mental health issues for students at Fern Creek High School

- 2011 Showing Tiger Pride Award, Fern Creek

- 2008 Fern Creek Alumni Association Outstanding Community Service Award

- 2008 Louisville Defender's Achievement Award

- 2008 JCPS Administrator of the year Award

- 2008 Harry J. Cowherd Award for Center Excellence

- 2007-2011 proposal funded by the City of Jeffersontown to help fund student programming and salary for Home School Coordinator.

- 2007-2011 proposal funded by the Fern Creek Alumni Association to help with student activities and personnel for Youth Services Center.

- 2007-2011 proposal funded by the Metro Council to also help with student programs and Personnel.

- 2007-2011 co-writer of the Health Promotions Schools of Excellence grant to fund healthy activities for students and staff

- 2007 Harry J. Cowherd Certificate of Merit

- 2006 Helped student write a proposal for Health Department to fund Smoke detectors for the bathrooms.

- 2005 Harry J. Cowherd Certificate of Merit

- 1999-2012 required to do state mandated updates for Youth Services Center Grant each year to ensure needs are being met for the students and families of Fern Creek Traditional High School and Carrithers Middle School. 
- 1999 Wrote \$90,000 grant for the Youth Connection Services Center which has now been open for 14 years and serves the students and families of Fern Creek Traditional High School and Carrithers Middle School.

- 1998-99 wrote "Youth as Resources" grant that enabled Fern Creek Elementary students and Fern Creek High School students to write, illustrate and bind story books together.

- 1998-99 wrote "School to Work" grant which gave 35 students the opportunity to do individual job shadowing and 64 participated in a group job shadowing experience. 